\title{
Competing or Collaborating Siblings? Industrial and Trade Policies in India
}

\author{
Gunjan Sharma* \\ August 2006 \\ Department of Economics \\ University of Missouri, Columbia
}

\begin{abstract}
This paper investigates the link between economic de-regulation-domestic as well as trade de-regulation-and firm-level productivity using two unique data sets. We use the industrial licensing regime in India (operating from the 1950s onwards) and its gradual relaxation during the 1980s and 1990s to test whether industrial de-regulation that leads to more competition domestically, affects firm-level productivity. To our knowledge, ours is the only detailed data set on Indian industrial policy. Our firm-level data for the period 1980-94 is a census of firms in India and has been rarely used in literature. We also use the interesting chronology of reforms in India (industrial de-regulation in the 1980s and trade reforms in 1991) to test whether industries that faced more competition domestically tend to perform better when facing foreign competition. Our identification strategy uses an important institutional feature of Indian policy. Firms with assets below a certain defined rupee threshold were exempt from licensing requirements. This institutional feature provides us within-industry variation that allows us to identify the interaction between de-licensing and exemption status. We find that industrial de-regulation during the 1980s led to a significant rise in firm productivity. Further preliminary results suggest that there exists a strategic complementarity relationship between industrial and trade policies-industries and firms that were de-licensed tend to perform better vis productivity after trade liberalization. Our results are robust to the inclusion of a wide variety of firm and industry fixed effects and controls for policies other than de-licensing that may affect productivity. This paper contributes to the literature by being the only detailed empirical analysis of the industrial licensing regime in India, especially the de-licensing that took place during the 1980s and by providing evidence of the crucial link between trade and industrial de-regulation.

JEL classification: F12, F14, D21, D42, L12, L51, O14, O38, O41
\end{abstract}

\footnotetext{
*Assistant Professor, Dept. of Economics, University of Missouri-Columbia. Email: sharmag @ missouri.edu. I would like to thank Dr. Roger Betancourt, Dr. Nuno Limao and Dr. Deborah Minehart for their immense support and guidance. Many thanks to Mr. B.S. Minhas, Mr. M.L. Sharma, Mr. P.C. Nirala, the Ministry of Programme Planning and Implementation, Government of India, and to officials in the Ministry of Commerce and Industry for their help and frank conversations. Special thanks to Dr. Arvind Panagariya and Dr. Aditya Mattoo for their comments and suggestions.
} 


\section{Introduction}

The impact of trade liberalization on growth, innovation and productivity has been intensely debated over the past few decades. This question is of immense importance to large and developing countries like India, China and Brazil that have recently entered the world economy. One way in which trade liberalization can impact growth and productivity is via the resulting increase in competition faced by firms (for example, Dollar and Kraay (2001), Frankel and Romer (1999), Sachs and Warner (1995)). However, the question of whether competition itself enhances firm-level incentives to innovate and grow more productive has been a matter of debate Nickell (1996)). Another important viewpoint stresses the role of domestic institutions and conditions in the success of trade reforms (for example, Rodrik and Rodriguez (2001)). This view avers that right institutions and conditions domestically can allow the achievement of superior economic outcomes.

In this paper, we are interested in the impact of domestic economic conditions and of trade reforms on firm-level productivity for the case of India. The specific economic condition that we investigate is the level of competition that a particular firm or industry faces in the domestic market. Then we assess the impact of competition from abroad (due to trade reforms). So the basic empirical questions that this paper tries to test are what is the first, most proximate impact of a rise in competition as a result of industrial de-regulation that a firm faces on a commonly used measure of productivity-output per worker and further, what is the relationship between domestic and foreign competition? Can the benefits from trade reform be enhanced by encouraging more competition within domestic industry?

As mentioned earlier, several large developing countries have recently undertaken trade liberalization and deregulation. Our case study-India-is particularly interesting and relevant for two reasons. Firstly, a very rigid and stern industrial licensing regime was in operation for 40 years. Entry to into manufacturing industry was not free (i.e. not based on market forces) and this in turn lead to monopolistic distortions in almost all sectors. The second feature that makes India a good case study for the relationship between trade and industrial reforms is the interesting chronology of reforms- industrial de-regulation in the 1980s and trade reforms in the 1990s. This chronology of reforms allows us to distinguish between the two types of reforms and to assess the relationship between them.

It is important to note that though there have been several studies of the impact of trade liberalization in India on firm-level productivity (e.g., Krishna and Mitra (1996), P. Balakrishan and 
Babu (2000), Sivadasan (2003)), this is the first attempt to assess the impact of the reforms of the 1980s. None of the previous studies control for the changes in the 1980s and hence provide biased estimates of the impact of trade reform. This issue is even more important in the light of a puzzling empirical result. As Panagariya (2002), Panagariya (2004) and Delong (2001) point out, reliable productivity measures show a sharp rise in productivity levels and rates of growth prior to the trade reforms of the 1990 s.

We use two unique data sets on India to test our predictions. The first data set on industrial policy in India from 1970 onwards is to our knowledge, the only comprehensive data set on industrial policy and one that allows econometric estimation of the impact of deregulation. We are able to identify which industry was deregulated in which year of the 1970s, 1980s and 1990s. Further we use a new plant-level data set for the period 1980-1994. This is a census of firms in India and has only recently been made available to researchers. The span of our data allows us to capture the impact of the reforms of the 1980s and the 1990s.

The specific predictions we test are derived from theory. In Sharma (2005) we use a two sector Schumpeterian growth model based on Aghion et al. (2005), Aghion et al. (2003) and Acemoglu et al. (2006) and we analyze firm-level incentives to invest in quality-enhancing technology. The intermediate goods sector invests in technology and the final goods sector production function includes both the quantity and the quality of these intermediates. In the benchmark case (Aghion et al. (2003)) the final goods sector is modeled as perfectly competitive and in this case, a rise in competition in the intermediate goods sector (modeled as a decline in the price to cost margin) always reduces firm-level incentives to invest in productivity-enhancing technology since the fall in price reduces the surplus that a firm can appropriate.

However this case may not be appropriate for the case of India. As mentioned earlier, entry into Indian industry was by no means free and the licensing regime created monopolistic distortion in almost all sectors. In order to provide a richer characterization of the economic environment in India, we model the final goods sector as a monopoly. This yields very different results from the benchmark case. Our first prediction is that given monopolistic distortion in the final goods sector, more competition in the intermediate goods sector (modeled as a fall in the price that the firm is able to charge for its product) can lead to rise in technological investment by the firm and hence to a rise in the productivity of the firm. The basic intuition behind this result is that once we allow the final goods sector to control its output and hence its derived demand for the intermediate goods, two forces operate on an intermediate goods firm. On the one hand, a fall in the price that 
it can charge reduces the surplus that it appropriates from a new technology and hence reduces investment in technology. But a lower price of its product raises the ex ante derived demand for its product from the final goods sector. This scale effect can be larger than the standard Schumpeterian effect under the condition that the initial level of monopolistic distortion in the intermediate goods sector is higher than a threshold level.

Our theory also gives us an indication of the impact of a rise in competition from foreign producers on the firm. Our second prediction is that under certain conditions, industries that face more competition domestically tend to perform better in the face of foreign competition. That is, there may be strategic complementarity between industrial de-regulation and trade reform. The intuition behind this result is that competition at home forces the firm to make investment in productivityenhancing technology and that these investments prepare the firm to compete with foreign entrants. The policy implication of this prediction is that it may be possible to raise the benefits from a trade liberalization episode by first facilitating greater competition domestically.

Our identification strategy uses an important institutional feature of Indian policy. Firms with assets below a certain defined rupee threshold were exempt from licensing requirements. Thus in any industry, some firms are "non-licensed" or "exempt" (since they are below the licensing threshold). So in industries that were "de-licensed" by the government, a firm is treated by delicensing reform only if it was large enough to be under licensing at the time of the reform. This institutional feature provides us within-industry variation that allows us to identify the interaction between de-licensing and size.

Given the nature of the licensing regime in India, the coefficient on this interaction gives the joint impact of two mechanisms through which de-licensing in India affected firm-level productivity. The first mechanism is the removal of direct, microeconomic constraints on the firm (for example, output limits) which impacted the ability of a firm to become more productive while the second mechanism is the removal of entry restrictions on the industry as a whole which impacted the incentives of firms to become productive.

Our main result is that piece-meal industrial de-regulation that took place in the 1980s has a positive and significant impact on labor productivity. Further, preliminary results suggest that there exists strategic complementarity between trade liberalization in 1991 and industrial de-regulation. That is, industries that were de-regulated tended to fare better after the trade liberalization episode.

We conduct a variety of robustness tests. Firstly, we test an implication of our identification assumption that for the group of industries where exemption from licensing was not granted, there 
should be no size-based response to de-licensing. Secondly, we analyze the distribution of assets and the rates of growth of assets of exempt firms over licensed and de-licensed industries and show that there was no difference between the response of exempt firms in the two types of industries. This means that the argument that firms sort their assets and hence their exempt status, based on anticipations of reform may not hold. We also provide evidence that there was no bunching of a large number of firms under the threshold and hence firms were not deliberately trying to stay exempt from licensing requirements. Another test of our identification assumption is that there should be no variation in the response of firms to de-licensing around arbitrary thresholds and we find that to be the case in our data. Our results are robust to the inclusion of a wide variety of firmlevel controls (ownership, organization, location (urban/rural and state) and wage to rental ratio) as well as industry-level controls (industry fixed effects, entry for firms belonging to large houses etc) that may affect firm-level productivity and/or be correlated with size. We also control for industrylevel time-varying factors (by including industry-year fixed effects). Since our data does not allow us to follow a firm over time, we use certain firm-level identifiers to create a pseudo-panel. We are able to identify several cross-sections of very similar firms in our sample. Using the pseudo-panel we check the robustness of our results to the inclusion of firm-level fixed effects.

De-regulation can change investment decisions and productivity by many different mechanisms. The one implied by our theoretical model is a reduction in the price-cost margin of the firm due to entry of new firms. Other mechanisms can include a rise in capacity utilization if the firm had excess capacity prior to de-regulation, a change in the capital to labor ratio in case regulation involved restrictions on the level of capital a firm could use in production, a decline in corruption that releases resources to be used for productive purposes etc. Though any full story about the impact of a de-regulation episode should include details of the mechanism through which de-regulation affects the firm, in this paper we focus on the impact of de-regulation not on the mechanisms through which this impact might occur.

The paper is organized as follows. Section 2 provides a brief literature review. Section 3 provides details about industrial licensing in India. Section 4 describes our industrial policy data set and the chronology of reforms as well as the firm-level data. Section 5 presents the empirical strategy. Sections 6 and 7 present the empirical results. Section 8 concludes the paper. 


\section{Literature Survey}

Our paper contributes to two main strands of literature. The first strand focuses on the impact of competition -domestic or foreign- on firm-level productivity and incentives. The second strand focuses on the impact of trade reforms on firm productivity.

There has been a stream of recent papers that examine the relationship between competition and productivity. Heterogeneous firm models highlight how competition could lead to higher aggregate productivity levels by forcing the exit of unproductive firms and leading to reallocation of resources from less productive to more productive firms (e.g., Hopenhayn (1992), Melitz (2003)). Representative firm models highlight broadly two channels through which competition could affect firm productivity: by providing better (worse) incentives for managers and workers to reduce slack and cut costs e.g, Schmidt (1997) or by providing better (worse) incentives for innovation or for adopting new technologies e.g., Aghion et al. (1999) and Aghion and Howitt (1992). This strand of literature has examined the relationship between product market competition and innovation. Aghion et al. (2001) analyze the interplay between innovation and product market competition and finds that product market competition (that is, how substitutable two goods are in the consumers demand function) enhances innovation in sectors where firms were already close to the technological frontier and discourages innovation in sectors where firms are below the frontier. Agh use a model of step-by-step innovation to find an inverted- $U$ shaped relationship between product market competition and innovation. This is supported by data on firms in the UK. Nickell (1996) reviews the studies that directly relate competition to productivity and finds a generally positive effect of competition on productivity. Djankov and Murrell (2002) review studies on the impact of product market competition on productivity in transition economies and find that in general more competition improves firm performance. Aghion et al. (2003), Aghion et al. (2004) and Aghion et al. (2005) use a Schumpeterian endogenous growth model to derive their main theoretical predictions. This model consists of a perfectly competitive final goods sector and a monopolistically competitive intermediate goods sector. They find that industries that were closer to the technological frontier pre-reforms tend to do better than other industries. Further, industries located in states that have pro-business policies (for example, a lower minimum wage) tend to perform better. Aghion et al. (2004)and Aghion et al. (2005) assess the impact of domestic deregulation on industry productivity for the case of India and find that industries that were deregulated tend to have higher productivity. 
Aghion et al. (2003), Aghion et al. (2004)and Aghion et al. (2005) are of particular relevance to our results. They assess the impact of the institution of minimum wage laws on firm-level investment and use the 1991 trade liberalization in India to illustrate how reform may have unequal effects on industries and regions. Their main theoretical results are that liberalization enhances investment in industries that were initially close to the technological frontier and that pro-worker legislation lowers investment and this negative effect is magnified by liberalization. Their empirical results confirm the main predictions of the model.

This paper contributes to this strand of literature in two ways. Firstly, most theoretical models do not try to model industrial policy in India and how this affected market structure and hence innovation incentives. The policy of close control of private sector initiative was in place for nearly 40 years and affected all aspects of production, distribution and even consumption. Our model tries to capture the effect of policy on market structure and the predictions of our theoretical model provide a richer characterization of innovation incentives.

In addition to this, we address the question of whether our results regarding domestic deregulation are eroded or enhanced as a result of competition from high technology foreign firms. That is, what is the interaction between domestic competition and foreign competition?

Secondly, contrary to Aghion et al. (2003), Aghion et al. (2004) and Aghion et al. (2005) who assess the impact of deregulation on industry productivity we use detailed firm-level data for the 15 year period. Further we have a detailed (and to our knowledge, the only) data set on Indian industrial policy from 1970 to 1994. Instead of analyzing the impact of isolated reforms (for example Aghion et al. (2004) use deregulation in 1985) we are able to analyze the impact of all changes in industrial policy in the 1980s and 1990s. We provide more details about our data in Section 4.

As in the case of increasing competition, theoretically trade liberalization could have both a positive as well as a negative impact on productivity. Thus the effect of trade liberalization on productivity is an empirical question. While the early evidence was somewhat mixed (Tybout (1992)), recent surveys by Tybout (2000) and Epifani (2003) conclude that the empirical literature generally support a positive effect of trade liberalization on productivity. For the case of India, several studies have used micro data to study the impact of trade reform on productivity ((e.g., Krishna and Mitra (1996), P. Balakrishan and Babu (2000)) and have come to very different conclusions. Krishna and Mitra (1996) who use firm-level data for the period 1986-1993 from several industries and find strong evidence of an increase in competition (as reflected in the reductions in 
price-marginal cost markups) and some evidence of an increase in the growth rate of productivity. P. Balakrishan and Babu (2000) use a sample of 2300 firms over the period 1988-89 to 1997-98 to find no evidence of acceleration in productivity growth as a result of the 1991 reforms. Das (2003) uses standard growth accounting on manufacturing industries during 1980-2000 and finds no evidence of change in TFP growth following the 1990Šs reforms. More recently, Topalova (2003) has used a more sophisticated methodology for calculating productivity and concludes that reductions in trade protection lead to higher levels of productivity in Indian manufacturing over the period 1989-2001. In a recent study Sivadasan (2003) uses a comprehensive and highly detailed firm-level data set and finds an 30 to $35 \%$ increase in mean intra-plant productivity level in tariff liberalized industries. There is also a $25 \%$ increase in aggregate output growth and a $20 \%$ increase in aggregate productivity growth following tariff liberalization.

We contribute to this literature by providing reliable estimates of the impact of trade reforms on firm-level productivity after controlling for the effect of domestic de-regulation. Other than Aghion et al. (2004) who use limited deregulation data for one year of the 1980s, none of the papers mentioned above control for the industrial de-regulation that took place in India during the 1980s. Hence their estimates of the impact of the trade liberalization of 1991 may be biased since some of the rise in productivity may have been due to de-regulation during the 1980s. Interest in the reforms of the 1980Šs has recently been revived due to a puzzling empirical result- As Panagariya (2002), Panagariya (2004) and Delong (2001) point out reliable productivity measures show a sharp rise in productivity levels and rates of growth prior to the 1991 sweeping reforms. In a recent paper Rodrik and Subramanian (2004) argue that the structural break in Indian growth came in the early eighties because there was an attitudinal shift on the part of the government towards a pro-business approach rather than due to actual policy changes like de-licensing. However they do not use data on policy reform to prove this hypothesis.

\section{Background on Indian Industrial Policy}

The licensing of industries was one of the major methods to control private enterprize in India. The mixed economy framework mandated a role for the private sector. However, it was felt that the private sector would need encouragement to invest in the desirable areas. Hence industrial licensing evolved as a method to direct investment in desirable directions. Details about the evolution of the system are presented in Appendix A. Here we present a brief description of the system and 
important changes.

A license was a document that permitted a firm to continue/begin production in an industry. It was issued by the Ministry of Industry in New Delhi. Under the Industries (Development and Regulation) Act 1951 (henceforth referred to as IDRA), all factories (defined as enterprises that did not use power but employed more than 100 workers or enterprises that used power and employed more than 50 workers) that were already operating or wished to operate in a specified list of industries were required by the government to obtain a license.

The scope of a license was fairly broad especially from the late 1960s onwards. Almost by definition, the licensing regime controlled entry into the industry and hence the amount of competition faced by a firm. Section 1 of Appendix A goes into details about the considerations of the licensing committee while debating a license. These were mainly macro-economic in nature and had little to do with the merits of the project. A license also specified the amount of output that a firm could produce. It was conditional on the proposed location of the project. Permission would be required to change location. The exact nature of the item to be produced was also specified and the firm needed to take permission or another license to change his product mix. Even the kind of technology and inputs that the firm could use in production (though not specified on the license) was determined because the most crucial raw materials (steel, cement, fuel etc) were controlled by the government and the firm needed to get annual allotments of these for production.

However, the effect of a permanent license to produce (combined with a low threat of potential entry) on firm-level incentives to reduce costs, modernize technology, improve quality and engage in monopolistic practices was raised by one committee after another starting from 1965, a mere 15 years after licensing was implemented. One of the earliest observations were made by the The Monopolies Inquiry Commission 1965 chaired by K. C. Dasgupta.

".....the requirement of law that new industries with capital over a specified amount $\check{E} \check{E}$ could not be started without a license is a formidable obstacle in the way of new entrepreneurs freely entering the lists." 1.

Further,

"The system of controls on the shape of Industrial licensing however necessary from other points of views, has restricted the freedom of entry into industry and so helped to produce concentration", 2 .

\footnotetext{
${ }^{1}$ Dasgupta (1965), page 7

${ }^{2}$ Dasgupta (1965), page 8
} 
Thus, the licensing regime in India affected firm-level productivity and costs through its control on both the firm's ability and incentives to innovate, reduce costs, adopt new technology etc. The direct controls on outputs and inputs affected ability and the indirect control of entry affected incentives. Even if the direct controls were not implemented fully due to corruption etc, the effect of the indirect controls on incentives was very large. Licensing restricted entry into most sectors and created artificial monopolies and oligopolies. The average four-firm concentration ratio in Indian manufacturing in 1981 was $54.2 \%$ compared to $32 \%$ for the US in 1977 . Even among developing countries, India seems to be closer to Poland (64.8\% in 1988) than Brazil (32\% in 1988).

\section{Data}

The data used in this paper comes primarily from two sources. In order to measure changes in the competitive environment faced by a firm (the right hand side explanatory variable), we have collected a detailed data set of industrial policy in India (to our knowledge, the only one existing) from the 1970s onwards. Using this data, we can identify which four-digit industry underwent reform (freedom from licensing requirements) in each year of the 1970s, 1980s and 1990s. The main source of data was internal government publications and notifications. Some commonly available publications like the Economic Survey were also used. Common publications, however, do not reveal the level of detail about the conditions under which firms were eligible to avail of certain policies. Study of government notifications, memos etc provided insight into the ideology of policy-makers and provided rich detail that we exploit in our identification strategy.

It is important to note that this is the first attempt to collect and compile data on Indian industrial policy for the period 1970-1995 in a manner that allows econometric estimation of the impact of policy changes. One reason for this is that detailed data on industrial policy pre-1991 are available only in obscure government notifications which are not easily available. Secondly, in the literature on India, the reforms of the 1980s are usually dismissed as too small and scattered to have had a significant effect on anything. There has not been a single detailed empirical study of these early reforms. As mentioned earlier, the reforms of the 1980Šs have been of great interest lately. Reliable productivity measures for India show a sharp rise in productivity levels and rates of growth prior to the 1991 sweeping reforms.

In the 1980s, the government started relaxing the licensing regime by "de-licensing" certain 
industries. From the late 1960s onwards it was starting to get clear that the strangle hold of regulation on Indian industry was fatal for it and many assessments of the system in the 1960s and 1970s advocated relaxation of regulations. Certain attempts were made in the $1970 \mathrm{~s}^{3}$. But it was in the 1980s that any significant change in the working of the system occurred. Table 1 shows the percentage of manufacturing output and value added that was de-licensed in each year of the 1980s and 1990s. We also show the percentage of factory output and value added that was de-licensed ( factories are defined as firms not using power and 100 or more employees and firms using power employing 50 or more employees) since under the IDRA 1951, only these factories were under the ambit of licensing.

This piece-meal approach to reforming industrial policy continued through the 1980s. In 1991, the Indian economy faced a balance of payment crisis and was forced to take loans from international organizations. Under pressure from these organizations, the biggest de-licensing episode occurred. Almost all industrial licensing was removed (other than for $16 \%$ of manufacturing output). Along with this, there was across the board reductions in tariffs and rationalization of non-tariff trade barriers. The rupee was de-valued by $22 \%$ (from Rs. 21.2 against the dollar to Rs. 25.8). The sheer scale and scope of the reforms were so large that this reform episode has been the one that has caught the imagination of policy-makers and researchers alike.

Table 1 brings forward two important points that challenge the predictions of other studies on India. The first is that with respect to the percentage of manufacturing output that they affected, the reforms of the 1980s were quite significant. Cumulatively, $23 \%$ of output and $23.6 \%$ of value added in 1990 had been de-licensed. Hence, studies that ignore pre-1991 changes in the licensing regime provide misleading estimates of the impact of the 1991 crisis. Secondly, de-licensing in 1991 was not "across the board" as is the common assumption in most studies. 16\% of manufacturing output and value added were still under compulsory licensing post-1991. Some of these industries were gradually de-licensed in 1993 and 1994. But studies that ignore the actual chronology of de-licensing post-1991 also overstate the impact of the 1991 crisis.

To measure the left-hand side variable-productivity of the firm- we use a rich and rarely used unit-level database. The source for unit-level data for this study is the Annual Survey of Industries conducted by the Central Statistical Organization (CSO), a department of the Ministry of

\footnotetext{
${ }^{3}$ The first "de-licensing" of firms was done in 1966 and by 1969, 41 items were de-licensed. However in 1973, these industries were licensed again and it was only in 1975 that the second phase of de-licensing began when 21 industries accounting for $3 \%$ of manufacturing output were de-licensed.
} 
Programme Planning and Implementation, Government of India. The survey covers all factories registered under the Factories Act 1948 (defined as units employing 20 or more workers). Note that the survey covers only the formal sector in Indian manufacturing. The ASI frame can be classified into 2 sectors-the census sector and the sample sector. Units in the census sector (all factories with more than 100 workers) are covered with a sampling probability of one while units in the sample sector are covered with probabilities one-half or one-third.

This rich unit-level database has been rarely used in literature since it has only recently been made available to researchers in electronic format. A recent paper that has utilized this database is Sivadasan (2003) who calculates the impact of the trade and foreign investment reforms that were done in 1991 on total factor productivity in Indian manufacturing. Most other papers (for example, Aghion et al. (2004)) use ASI data at the industry-state level.

We obtained this data for the 14 year period 1980-81 to 1994-95. The length of our data allows us to cover all the reforms of the 1980s as well as the major reform episode of 1991. The data is reported on a financial year basis. That is, 1980-81 refers to the period between 1 April 1980 and 31 March 1981.

For our analysis, we use all unit-level data on all factories as defined by the Industries (Development and Regulation) Act 1951 since these units were the ones that came under the ambit of industrial licensing. These are units that employ 50 or more workers and use power in the production process or units that employ 100 or more workers without the aid of power. The non-factory units that we exclude are large in number (an average of $30 \%$ over our time period) but account for only $14 \%$ of total output and $18 \%$ of employment in registered manufacturing.

Since we use log of output per worker, observations for which the output or worker figures are less than or equal to zero are excluded from the analysis. Further, 42000 firms are listed as being closed in the year of the survey and these are also excluded from the analysis.

The basic characteristics of the data that we use for our analysis are summarized in Table 2. As mentioned earlier the census sector of the ASI comprises of units employing 100 or more workers while our subset consists of units employing 100 or more workers without power and 50 or more workers with power. Thus, nearly $80 \%$ of our data has a sampling probability of one. On average there are around 15000 units a year corresponding to a population of 20000 units. Note that the sampling scheme changed in 1987. In all our analysis, we weight observations using the multiplier or the inverse sampling probability to adjust for sampling frequency. Summary statistics of our key variables are presented in Table 3. 
Real output is measured as value of total output measured in 1993-94 prices. The deflator used is the sector specific wholesale price index ${ }^{4}$. Labor is measured as the number of employees.

\section{Identification Strategy and Estimation Equation}

\subsection{Estimation Equation}

The prediction from our theoretical model that we want to test is that a more competitive domestic environment forces firms to raise their investment in productivity-enhancing technology and hence leads to higher productivity. As explained in Section 3 the industrial licensing regime in India affected market structure and market power of firms operating in the manufacturing sector, mainly through restriction of entry. It also affected investment incentives of firms via its control of firm output, location, raw material usage etc. Thus, a removal of licensing requirements from an industry led to a more competitive, market-driven environment. After controlling for industry and year effects, the estimation equation that this translates into is given by

$$
y_{i j t s}=\beta_{0}+\alpha_{j}+\delta_{t}+\beta_{1} D e_{j t}+\eta X_{i j t s}+\varepsilon_{i j t s}
$$

Here $Y_{i j t s}$ is the $\log$ of output per worker for a factory $i$ producing in industry $j$, located in state $s$ at time $t$. De $e_{j t}$ is an indicator that takes in a value of one in all years greater than equal to year $t$ if industry $j$ was de-licensed in year $t . \alpha_{j}, \delta_{t}$ are industry and year effects. The vector $X_{i j t s}$ contains other firm, industry and state level controls. We explain these controls in detail in Section 5.5.

\subsection{Identification Problem and Strategy}

There are important reasons why the estimation of Equation 1 may not give unbiased, consistent estimates. Note that main explanatory variable $D e_{j t}$ varies at the industry level. Political economy factors like political affiliation, lobbying power etc are also at the industry-level and these might affect whether industry $\mathrm{j}$ gets de-licensed. Industry-year fixed effects may capture some of these un-observables. However, in order to get reliable estimates we need within-industry variation.

The other reason has to do with the nature of the reforms on the 1980s. The reforms of the 1980s have been characterized by some as "reforms by stealth". There was no consensus for economic reforms in the 1980s. It is clear from policy documents that the government was at pains to portray the changes of the 1980s as a continuation of the existing system (even though these were dramatic

\footnotetext{
${ }^{4}$ Source: various issues of the Reserve Bank of India Bulletin
} 
changes that veered away from the high-regulation, socialist paradigm in operation). Under these circumstances it is possible that the government was choosing industries for de-regulation based on certain characteristics that either raised the chances of the success of the reforms (for example, picking high productivity industries) or that minimized social costs in case of failure (for example, picking high technology industries to minimize employment effects).

Our identification strategy uses important institutional features of industrial policy in India. Firms that had assets in plant and machinery, land and building less than a certain amount were free ("exempt" in official parlance) from industrial licensing requirements. This was an important component of the government's strategy to promote the growth of smaller firms that would be main engine of employment generation in the manufacturing sector. These firms would also satisfy consumption needs of the economy and would be a mechanism to spread economic growth to farflung regions of the country. Further, this was also a pragmatic decision so that the administrative burden of the licensing regime did not grow too large. By the late-1960s, as the manufacturing sector took off, there were reports of long delays in the grant of licenses. By giving exemption to some firms, the intent was to lessen the sheer volume of applications that the licensing authority had to process. Note that these exempt firms could enter and operate in any industry and without restrictions on output or investment as long as they stayed below the threshold ${ }^{5}$. This meant that in each licensed industry there is a group of firms that is not under licensing. We call these the "exempt" firms.

Further, in the 1980s certain industries were "de-licensed". That is, all firms (irrespective of whether they were exempt or not) were freed from licensing requirements in these industries. In terms of our identification strategy, this means that from 1984 onwards all firms in certain "delicensed" industries were not under licensing requirements.

Keeping in mind the institutional features of industrial policy in India, in each de-licensed industry there is a group of firms that are not affected by the reform since they were not under licensing to begin with (the exempt firms). So the industry in which a firm produces as well the firm's exemption status jointly determine the firm's exposure to de-licensing.

To sum up, a firm is treated by de-licensing reform in industry $A$ in year $t$ if

- Industry $A$ was de-licensed in year $t$.

\footnotetext{
${ }^{5}$ In some cases, certain additional conditions like upper limits on foreign exchange requirements for the project needed to be fulfilled in order for the firm to be "exempt". But these conditions were by and large easy to fulfill and according to officials, a large number of firms were able to take advantage of this scheme.
} 
- The firm was under licensing to begin with. That is, it was not granted an exemption from licensing.

The criterion for exemption was in terms of the original rupee value of plant and machinery, land and building owned (or proposed to be owned) by the firm. This definition was constant for all industries. That is, an exempt firm in industry $A$ would face the same threshold as an exempt firm in industry $B$. Over our sample period 1980-1994, the rupee value of this definition was changed twice-in 1983-84 and 1990-916 ${ }^{6}$. From the period 1980-81 to 1982-83, a firm whose assets in plant and machinery were worth less than of equal to Rs. 30 million was defined as small. In 1983-847, the threshold was increased to Rs. 50 million and in $1990^{8}$, to Rs. 150 million. Note that inflation in the price of land or machinery would not change the exempt/not-exempt status of the firm since this was based on the original or book value of assets (not current value).

However, this "exemption" from licensing was not available to firms in a group of industries referred to as Schedule IV and Schedule V industries ${ }^{9}$. Schedule IV included industries like textiles produced on power looms that were items of mass consumption over whose production, pricing and distribution the government wanted close control. Schedule V industries were the industries that were deemed to be using "scarce" raw materials (imported or domestic). So in these industries, all firms were under licensing. We do not include these industries in our main estimation equation but we use them to provide a test of our identification assumption.

Thus the actual equation that we estimate is

$$
y_{i j t s}=\beta_{0}+\alpha_{j}+\delta_{t}+\beta_{1} D e_{j t}+\beta_{2} N o t E x e m p t_{i t}+\beta_{3} D_{j t} N_{\text {NotExempt }}+\eta X_{i j t s}+\varepsilon_{i j t s}
$$

Here NotExempt ${ }_{i t}$ takes on a value of one when the firm is not exempt from licensing requirements. Our identification strategy allows us to deal with the problem that industry-level unobservables may make $D e_{j t}$ correlated with the error term. If we suppose that there were unobservable factors that determined whether industry A was de-licensed in year $\mathrm{t}$, as long as these factors were industry-specific they should be same for all firms within industry A. That is, a exempt firm $\left(\right.$ NotExempt $\left.t_{i t}=0\right)$ in industry A has the same un-observables as does a non-exempt firm

\footnotetext{
${ }^{6}$ In May 1990, in an Industrial Policy statement the government raised the exemption limit to Rs. 500 million. However, in November 1990 a new government came to power and by April-May 1991, the foreign exchange crisis was taking hold. Given these two factors, the implementation of the May 1990 statement in actual practice is in doubt.

${ }^{7}$ Ministry of Industry Notification S.O. 328(E) dated 23 April 1983

${ }^{8}$ Economic Survey 1990-91

${ }^{9}$ Government of India, Ministry of Industry Notification 16 Feb, 1973. S.O. 98(E)/IDRA/29B/73/1 specifies these industries and the subsequent changes to these lists were gathered from amendments to this notification as well as other notifications and press notes issued by the government.
} 
$\left(\right.$ Not Exempt $\left.t_{i t}=1\right)$ in industry A. Thus, any variation in productivity around the threshold for licensing should come from de-licensing. Thus, co-efficient $\beta_{3}$ on the interaction of size and de-licensing $-D e_{j t}$ Not Exempt ${ }_{i t}-$ is identified.

As mentioned in Section 3, the licensing regime affected both the ability as well as the incentives of a firm to invest in productivity. The controls on the amount of output, the location of the plant, the technology used etc directly controlled the ability of a firm while controls on entry into an industry affected incentives. When an industry was de-licensed, both these controls were removed simultaneously. In this context, the coefficient $\beta_{3}$ captures the impact of the relaxation of both direct and indirect controls on firms. That is, $\beta_{3}$ measures the impact of de-licensing on a non-exempt firm's productivity because of relaxation of output, locational and other constraints as well as the impact on productivity due to more competition and a higher threat of potential entry.

The first mechanism-relaxation of direct controls on the ability of a firm-makes sense since only the not exempt firms were under the burden of fulfilling onerous conditions on output, location etc while exempt firms were not (as long as they maintained assets below the government definition). Thus, there is differential impact on these two types of firms within an industry of de-licensing.

The argument with regard to the second mechanism-higher threat of potential entry-is more nuanced. One might argue that if there were no barriers to entry as a small, exempt firm while there were huge barriers to entry as a large, not exempt firm (in the form of the cost of procuring a license) then no firm would want to enter as a not exempt, large firm in the pre-reform period. All firms would enter small and would grow until they reach the threshold amount of assets. This means that de-licensing will not increase entry into the ranks of not exempt firms while exempt firms have free entry both pre- and post-reforms. If this were the case then our identification strategy does not capture the impact of entry de-regulation on the productivity of firms.

However, the argument above assumes that there are no costs to entering as a small, exempt firm. This assumption is not likely to be true because a license to produce was only one in a whole package of permissions and permits that a firm needed to get in order to commence production. For example, in order to get exemption firms needed to agree to an upper limit on foreign exchange requirements. Further, on the basis of the recommendations made by the licensing committee, the firm had to get allotments of essential raw materials from another committee that was in charge of allocations. Similarly, the firm needed to go through a separate procedure to get permission to procure foreign exchange and to import any raw materials or machines. Further, the firm needed to 
get financing for its project but applied to financial institutions after getting all the required permits and licenses. All these procedures and permissions were more likely to be more difficult and costly for a small firm. So if a firm decided to enter the industry as small, the firm not only suffered the loss of economies of scale but also faced additional costs of being small. Thus, while there were no explicit entry barriers into the exempt category of firms, the other accoutrements of the licensing and trade regime created entry barriers and it is by no means obvious that a firm would always want to enter small in size, pre-reforms. This means that de-licensing of an industry reduced entry barriers for both of exempt as well as not exempt firms and that our empirical strategy catches these effects.

Our identification strategy has been used extensively in the evaluation of social programs in developing countries. Similar strategies have been used in the public finance literature to evaluate the effect of public policies. Rosenzweig and Wolpin (1988) first proposed the use of fixed effects methods for evaluating the impact of public programs in developing countries. Gertler and Molyneaux (1994) applied these methods to the problem of estimating the returns to family planning programs by controlling for unobservable region-specific cultural and religious norms. Duflo (2000) uses this strategy to evaluate returns to a school-building program in Indonesia. She uses variations in program intensity over regions as well as the date of birth to identify individuals who would be most affected by this program. Children who were at or below the school-going age at the time the program was implemented will benefit more than children who were older. Further, this difference is higher in regions that received more schools. Angrist and Evans (1996) use a similar strategy to identify the effects of state abortion reforms on labor market outcomes. The causal relationship they want to identify is between teen-child bearing and labor market outcomes. They create an instrument for teen child-bearing that is an interaction of the state of birth and the year of birth. The latter captures the exposure that a woman had (in her teen years) to liberal abortion environment. So women with more years of exposure to a liberal environment are less likely to be teen-mothers than women with less years of exposure. However this difference is likely to be more in states that reformed their abortion laws. More recently, Visaria (2004) uses this strategy to identify the effect of judicial quality on economic outcomes. The sources of variation in her application are the monetary threshold for claims to be eligible for these tribunals, and the staggered introduction of debt-recovery tribunals across Indian states.

The Indian reforms of the 1980s are well-suited to the use of fixed-effects methods because the variations in the regulatory environment come from a well-defined series of reforms. This makes 
it possible to test an implication of the identification assumption that any variation in performance of firms due to de-licensing should come around the actual exemption status. We use a group of industries where all firms were under licensing i.e. no firm was granted an exemption. For this group of industries, since the threshold for exemption did not apply, the co-efficient on the interaction of $D e_{j t}$ and NotExempt ${ }_{i t}$ should be insignificant. That is, there should be no variation in the response to de-licensing around the exemption threshold. The results of this specification test are reported in Appendix C.

\subsection{Exogeneity of Exemption Status}

In order to get unbiased and consistent estimates from Equation 2, we need to make sure that the sources of variation in our data are exogenous. The first issue was that of omitted variable bias that may make the de-licensing dummy endogenous. To solve that we use an institutional feature of Indian policy making, as explained in the previous section.

However, a second source of bias arises from the possibility that firms may be endogenously choosing their exemption status (i.e. the size of their assets in plant, machinery, land and building) based on anticipations of de-licensing. Suppose that the main benefit to a firm for choosing a low level of capital comes from the fact that the firm is free from licensing requirements. Then if the firm is truly constrained by the threshold and is anticipating de-licensing of its industry (when it will loose its privileged status) it will increase its capital even if that means that it is above the threshold.

There are several reasons why an exempt firm will want to increase its capital if it anticipates de-licensing. The first is that if the main reason why the firm is keeping a low capital stock is to escape from licensing then as soon as this privilege is removed, the firm will no longer benefit from constraining its capital and hence will want to expand. Another reason is that de-licensing means that the firm will be competing in an environment of free entry for larger firms (remember that exemption was only for "smaller" proposals). In order to compete it might be necessary to take advantage of economies of scale and that might entail increasing its assets. In the sections below we investigate the possibility that firms chose their assets in anticipation of de-licensing of their industry. If this is the case, there should be a difference in the distribution of firms over industries. Industries that were de-licensed should have a lower proportion of exempt firms (as these firms raise their assets in plant, machinery, land and building because they no longer stand to gain from having low assets). Further, the rates of growth and levels of assets of exempt firms should be 
higher in de-licensed industries post-reform.

The first important point to note about de-regulation reforms in India is that there was an exogenous break in the pattern of de-regulation in 1991. Up to 1991, de-licensing was done in a piece-meal manner-a few industries each year. The extent of the balance of payment crisis in 1991 and the conditions attached with foreign loans were completely exogenous. By far the largest de-licensing episode occurred in 1991. Thus, it seems unlikely that firms would be choosing their assets endogenously with respect to the de-licensing in 1991. Thus, in our discussion of endogeneity of exemption status we focus on de-licensing episodes in the 1980s.

With regard to the reforms in the 1980s, we conduct a number of tests of the exogeneity of exemption status, in terms of size of assets. An analysis of the data reveals little evidence of firms choosing their assets (and hence their exemption status) in anticipation of de-licensing.

(a) In the industries that were de-licensed during the 1980s, the proportion of exempt firms was 0.95 pre-reform (1980-83) and it fell to an average of 0.93 during the reforms (1984-89). This pattern was identical to that in industries that were not de-licensed in the 1980s (here the proportion of exempt firms fell from 0.97 to 0.95 ). That is, there was no sudden inexplicable decline in the proportion of exempt firms post-reform. Similarly, the average annual rate of growth of the number of exempt firms also maintained its pattern across industries (It rose from $1.6 \%$ to $2.4 \%$ in the de-licensed industries and from $-1.5 \%$ to $0.5 \%$ in the still-licensed industries.).

(b) In Table 4 we investigate the pattern of the average annual rates of growth of assets in plant, machinery, land and building across exempt firms. We see that while the rate of growth of the mean is higher in de-licensed industries as compared to licensed industries, the top $25 \%$ of firms grew faster in licensed industries than in de-licensed industries during 1984$89(12.97 \%$ as compared to $10.53 \%)$. This is contrary to what we would find if firms were choosing their assets based on reforms. Similarly in the top $50 \%$ of firms, the rate of growth of assets is slightly higher for exempt firms in licensed industries. Thus, in firms that were closer to the threshold-and hence more likely to be endogenously choosing size- there is little or no difference in the behavior of growth of assets.

(c) In Figure 1 we investigate the distribution of exempt firms over assets in industries in two year-1983 (the year preceding the first deregulation episode) and 1988 (the year immediately 
after the reforms of the 1980s). Within each graph the solid line represents the year 1988 while the dashed line represents the year 1983. We see that the distributions are very similar in de-licensed industries as compared to licensed industries. This is especially true towards the end of the distribution i.e. nearer to the threshold.

Note that there is a large mass of firms with very little assets in plant, machinery, land and building. To get a clearer idea of the effect of reforms on the distribution of assets, in Figure 3 we present the distribution assets of firms with assets below Rs. 4.5 million (ie. the really small firms) and in Figure 2 the distribution of assets of firms with assets greater than Rs. 4.5 million but less than the threshold amount of Rs. 50 million $^{10}$. We see that the distribution of really small firms (Figure 3) in de-licensed industries is quite different from the distribution in licensed industries especially in the lower range. But this difference is constant over time i.e. it holds for both years. Towards the end of the distribution, in both types of industries, the density is higher in 1988 as compared to 1983.

In Figure 2 again we see that the distribution of assets is very similar in licensed and delicensed industries especially as assets rise. Towards the beginning of the distribution (i.e., for firms with assets close to Rs. 4.5 million), licensed industries tend to have a higher density in 1988 while de-licensed industries tend to have lower density. But the important point to note is that this difference crops up very far from the threshold of Rs. 50 million. For firms closer to the threshold and hence more important for us with regard to the potential problem of endogeneity, the distributions are very similar.

Thus we see that the behavior of exempt firms with respect to assets in plant and machinery, land and buildings is not different over de-licensed and licensed industries ${ }^{11}$. Hence the argument that firms may choose size in anticipation of de-licensing does not seem to hold in our data.

(d) Other evidence against this argument arises from an analysis of whether the threshold (on assets in plant, machinery, land and building) implemented by the government was binding for exempt firms. If there was a large mass of exempt firms that were on or slightly below the

\footnotetext{
${ }^{10}$ We choose the threshold of Rs. 4.5 million since this categorization was used by the government to define "small" firms. These firms were given special assistance and encouragement from the government. In this respect it is interesting to analyze the behavior of these firms. We also analyzed the behavior of exempt firms around randomly chosen thresholds and our findings are similar. There is little difference in the behavior of exempt firms (no matter how far from the actual threshold) across licensed and de-licensed industries.

${ }^{11}$ We also analyzed the distribution of other firm characteristics like assets in plant and machinery and employment over exemption status and industries. Here too we find that the patterns are very similar in de-licensed industries as compared to licensed industries.
} 
threshold and were maintaining low levels of assets deliberately then the magnitude of the endogeneity problem is bound to be quite large. However as we demonstrate in Appendix $\mathrm{B}$, we do not find any evidence of bunching below the threshold for licensing. We do not find a large mass of firms directly below the threshold ${ }^{12}$. The threshold is binding only for the top $1 \%$ of firms (that too with a utilization rate of only $80 \%$ ) and utilization rates drop of sharply for the other percentiles. Further, there is no evidence to suggest that firms directly above the threshold (and hence, licensed) were racing to raise their assets in plant and machinery-another indication that the asset limits might not be constraining ${ }^{13}$.

\subsection{Comparability of non-equivalent groups}

Our empirical strategy depends on the difference in performance between exempt and not exempt firms in response to de-licensing. However exempt and not exempt firms are different in a crucial dimension-size. Hence we are concerned that there may be other variables, other than de-licensing that may lead to any differential response between exempt and not exempt firms. In order to check the equivalence of these two types of firms, we conduct a series of simple tests. We find that in terms of trends of major variables as well as the evolution of the distribution of major variables, not exempt and exempt firms behave in a similar manner particularly in the pre-reform period. That is, there are differences in exempt and not exempt firms but that these differences do not change over time or due to any other variables in the pre-reform period. In Figure 6 we show the trends in average output per worker for exempt and not exempt firms. As we can see, exempt firms exhibit the same broad trends in productivity over time as not exempt firms particularly in the pre-reform period (1980-84).

Further our analysis of the trends in productivity for exempt and not exempt firms over various dimensions (industry, location, ownership etc) shows that both types of firms tend to more together over time. For example, in Figure 8 we show the time trends in productivity for exempt and not exempt firms for two-digit industries and in Figure 7 for firms with different ownership structures. These figures reveal that the basic trends in productivity for exempt and not exempt firms are broadly similar along several important dimensions particularly in the pre-reform period 1980-84.

\footnotetext{
${ }^{12}$ In Appendix B we also conduct this analysis for the capital to labor ratio and find that there is no bunching of firms around the average capital-labor ratio (as implied by the threshold) within an industry and year.

${ }^{13}$ This point should not be taken to imply that the licensing regime itself was not binding since firms were not trying to escape it. As pointed out in Section 3, the licensing system controlled two things at the firm-level-a firms ability (via control of the amounts of capital, output etc) and a firms incentives (via control of entry into the industry).
} 
Thus, exempt firms can be used as a comparison group for not exempt firms. There are ex ante differences in the levels of productivity but these are generally constant over time ${ }^{14}$.

\subsection{Controls}

In this section we talk about the controls that are included in the $X_{i j t}$ variable in Equation 2. We use our industrial policy database to control for policies that may affect the ability and/or incentives of the firm to raise its productivity.

\section{- Policies regarding dominant firms and firms belonging to large and/or foreign owned} industrial houses. Control of large private industry was an important objective of policy in India. The main objective was to prevent the concentration of economic power in a few private hands. Since the inception of the licensing system, certain large industrial houses were considered dangerous and hence all licensing proposals from these houses were treated with suspicion. In 1973, the government streamlined its policies regarding large industrial houses and announced a list of industries in which large and/or foreign owned houses were allowed to operate ${ }^{15}$. We control for this list of industries in which large and/or foreign owned houses were allowed to operate. We define

$$
\text { Large }_{j t}= \begin{cases}1 & \text { if industry } j \text { was open for large houses in year } t \\ 0 & \text { otherwise }\end{cases}
$$

- Controls for the ownership and organization structure of the firm. Controls for these are included since the ability to take productivity enhancing decisions and the flexibility that a firm has in adapting to a changed policy environment may depend on whether the firm is owned by the government or by the private sector. 16

- The location of a firm is another important variable that maybe correlated with its productivity or its size. In addition to controlling for the state in which a firm is located, we also control for whether it was located in an urban, rural or metropolitan area. It is possible that the level of infrastructure that are available to a firm is different if it is located

\footnotetext{
${ }^{14}$ Figures and data with respect to other dimensions like location, organization etc available upon request.

${ }^{15}$ Even in these industries, the stated policy was one of preference for non-large firms. If a large house wanted to set up a firm in an industry not on this list then it would have to undertake an export obligation of 60-75\% of output.

${ }^{16}$ For ownership, there are 6 categories-owned by central government, owned by state government, jointly owned by state and central government, wholly privately owned, joint sector firm with majority private ownership and joint sector firm with majority public ownership. Organization includes individual proprietorship, joint family run, other partnership, public limited firm, private limited firm, public corporation, co-operative society and other.
} 
in an urban area as compared with a rural area and this in turn maybe correlated with the productivity of the firm. We define $\operatorname{urban}_{i}=1$ if firm $i$ is located in urban area, 0 else and metro $_{i}=1$ if firm $i$ is located in metropolitan area, 0 else.

- One issue that we are concerned with is the relationship between the size of the firm and the productivity of the firm. In particular, productivity of the firm as measured by output per worker may be determined by its size. If we were to measure size by output then this would be true by definition. Our definition of size however, is based on the assets of the firm in plant and machinery. But it is still possible that output per worker (our measure of productivity) is affected by capital per worker (for example, in any linear homogenous production function) and so size (and hence exemption status) and productivity are directly related. We cannot directly put the capital-labor ratio in our estimation equation (since the variable $N e_{i t}$ is a function of capital). So we need a proxy for the capital to labor ratio in our estimation equation.

We use the average price of capital relative to price of labor in a state $\mathrm{s}$ in year $\mathrm{t}$. We use the deflator for net fixed capital formation (with base 1993-94) ${ }^{17}$ as a proxy for the price of capital. In our unit-level data we have the wage bill as well as the number of workers employed by each unit. So we are able to impute the annual wage rate that a firm has to pay. Since this wage rate is in nominal terms we deflate it so that it has base 1993-94 (similar to our measure for price of capital). The reason why we use state-year averages of this cost ratio is because firm level cost ratios might be endogenous with technology and productivity choices of the firm. Further, labor laws (for example, minimum wage) and their implementation is at the state level. So the average cost ratio captures the major institutional features of the labor market in India.

\section{Results}

\subsection{Main Results}

In Table 5 we present our baseline results for the estimation of Equation 2. In each specification we have included all the controls mentioned in the previous section. These regressions are withinindustry. That is we are estimating a firms performance as the average performance of the 4-digit

\footnotetext{
${ }^{17}$ Source: National Account Statistics
} 
industry to which the firm belongs. We have also included year and state fixed effects. Standard errors are clustered around four-digit industry. Column 1 of Table 5 shows the results of our main specification on the sample of factories, excluding Schedule IV and Schedule V industries. Thus we see that on average firms that were not exempt from licensing and were in de-licensed industries had $16.1 \%$ higher labor productivity. Our estimate is significant at the 5\% level. That is, industrial de-regulation leads to a significant rise in the firm productivity.

In Column 2 of the table we present regression results for the period 1980-90. Note that an important point of our analysis is that the reforms of the 1980s have been unfairly ignored by the literature. So it would be interesting to see the impact of those piece-meal reforms on productivity, not the path-breaking reforms of 1991. We find that the average firm that was treated with delicensing during the 1980s did better than a non-treated firm. However this effect is significant only at the $17 \%$ level. Thus, the reforms of the 1980s did have some impact on firm productivity but this effect was small. Note that the total impact of de-licensing $\left(\beta_{1}+\beta_{3}\right)$ is very small for the period 1980-90. One possible rationalization for this small impact on productivity during the 1980s could be the lack of an enabling environment. That is, a rise in domestic competition can change the incentives of the firm to raise its productivity but this effect is reinforced by other factors. One such important factor that we will investigate is competition from abroad i.e. trade reform.

However, different industries may have very different productivity paths and that our coefficient may be capturing some of this time-varying heterogeneity. In Column 3 we check the robustness of our results to the inclusion of 3-digit industry specific time trends in addition to year effects. In Column 4 we report the results for the year 1980-90 after including industry-specific trends. We see that the interaction term is considerably lower in magnitude and is significant at the $10 \%$ level. Thus, even after controlling for time-varying growth paths in different industries, we find that firms that were affected by de-licensing had higher labor productivity than firms that were not affected. For the 1980s, the coefficient on the interaction is positive and insignificant.

Thus our baseline results support our intuition and the first prediction from our theory-firms in more competitive, deregulated industries tend to have higher productivity. An important point to note from Table 5 is that in all the specifications, the average impact of de-licensing on all firms in the industry (the coefficient on $D e_{j t}$ ) is negative. That is, industries that were deregulated have lower productivity on average compared with industries that were not deregulated. It is the not exempt firms (that were under licensing) that see a rise in their productivity after de-licensing. But 
in almost all cases, the total effect $\left(\beta_{1}+\beta_{3}\right)$ is positive $^{18}$.

From Table 5, the role of exemption status also becomes clearer. In all the specifications the coefficient on NotExempt ${ }_{i t}$ is large and positive. That is, not exempt firms had higher productivity than exempt firms. This could be a reflection of the economies of scale enjoyed by larger firms.

As a quick check of the validity of pooling exempt and not exempt firms in one regression, we also estimated Equation 2 (not reported, available by request) for the individual groups of exempt and not exempt firms. The coefficient on the reform variable is positive and significant for not exempt firms while it is small and negative for the exempt firms. This is consistent with our findings in the pooled sample that not exempt firms which were under licensing to begin with perform better after de-licensing in their industry as compared with exempt firms in their industry.

In Appendix $\mathrm{C}$ we show the results of the basic regression for Special industries. These were industries in which there was no distinction between exempt and not exempt firms. This allows us to test an implication of our identification strategy that there should be no variation in the performance of exempt and not exempt firms due to de-licensing of special industries. We find that this is the case in our data.

In Appendix D we provide details of another specification test. One implication of our identification assumption is that if we choose arbitrary thresholds for exemption from licensing, then we should not find any variation in the response of firms to de-licensing around these arbitrary thresholds. That is, if the true threshold matters then randomly chosen thresholds should not. We find that this is true in our data. The significance level of the interaction coefficients when plotted against distance from the actual threshold takes a bell-shape. That is, the interaction between delicensing and the random threshold (both above and below the actual threshold) is insignificant far from the actual threshold and rises in significance as we approach the true threshold.

Our baseline results are robust to a variety of checks which are presented in Table 6. One of the first things that we may be worried about is the possibility of sample selection. In our main regressions we are excluding firms in Schedule IV and V industries. It is possible that the Schedule IV and Schedule V industries (which did not have exemptions from licensing for any firms) may have special characteristics that may be correlated with size or with productivity. As we see in Appendix C (Column 2, Table C.1), the coefficient on the interaction of de-licensing

\footnotetext{
${ }^{18}$ The fact that $\beta_{2}$ is negative in all the specifications might point towards the fact that the government was choosing low productivity industries for de-licensing. This means that our coefficients may still be biased due to industryspecific un-observables. However industry-year fixed effects can capture these omitted industry-level factors and our results are robust to these effects for the 1980s as well as for the full time span 1980-94 (Columns 1 and 2 of Table 6).
} 
with exemption status for non-schedule IV and V industries is significant and positive even when we include Schedule IV and V industries separately ${ }^{19}$.

In Table 6, Columns 1 and 2 we subject our results to a strict check. We are not satisfied that industry-specific time trends capture all the industry-specific heterogeneity that we may falsely attribute to reforms. Hence we include 2-digit industry-year effects into our main regression as well as in the regression for the years $1980-90^{20}$. We find that magnitude of the interaction coefficient is lower than the baseline specification but it is still quite large and significant at the $10 \%$ level. For the period 1980-90, the coefficient on the interaction is positive and significant at the $19 \%$ level. There is also a possibility that our results may be driven by some outliers. Column 3 of the table shows the results of our main regression when we winsorize the dependent variable by $1 \%$.

When we control for industry-year effects (Table 6), we are worried that the time paths of growth might be highly dissimilar across industries and we wish to control for that. In Column 4 of Table 6 we subject our result to a stricter check. We include industry-state-year effects. Our concern is that industries in different states may have different time paths of growth. This could be due to different growth paths of infrastructure, financial markets, labor laws, wage to rental ratios etc in different states. These factors may affect the incentives and the ability of firms located in different states differently. If de-regulated industries are disproportionately located in states that have higher growth rates of these variables then we maybe falsely attributing this to the reforms (rather than to the growth of these variables). We find that after controlling for three-way 3-digit industry, state, year effects the average affected firm (with $N e_{i t} D e_{j t}=1$ ) still has higher productivity than others. Further note that in this specification the average impact of de-licensing $\left(\beta_{1}\right)$ is positive. That is, after controlling for industry-state-year interactions all firms in de-licensed industries performed better than firms in licensed industries. This means that the total impact of de-licensing $\left(\beta_{1}+\beta_{3}\right)$ is quite large.

\subsection{Controlling for firm-level un-observables}

A very important source of bias in our co-efficient estimates may be due to reverse causality. The main causal story that we want to tell is that the productivity of a firm that was under licensing

\footnotetext{
${ }^{19} \mathrm{We}$ also tried regressions including non-factories in the sample. Our results are robust to the inclusion of these firms.

${ }^{20} \mathrm{We}$ also test our results using 4-digit industry effects interacted with year effects. Note that this means that the coefficient on $D e_{j t}$ is not identified. However the interaction term $D e_{j t} * N e_{i t}$ is identified and the coefficient on it is 0.15 and is significant at the $1 \%$ level.
} 
requirements $\left(\right.$ NotExempt $\left._{i t}=1\right)$ and was in an industry that was de-licensed by the government will be affected by de-licensing. However, it may be that a firm of a particular productivity may chose to be exempt from licensing. That is, firms that have low productivity may have a systematic tendency to stay exempt from licensing requirements since that keeps them protected from the larger, licensed firms. Then, since low productivity firms are choosing to be "non-treated" firms, we will see a large effect of de-licensing even if it did not have a large impact. That is, our estimates of the impact of de-licensing are biased upwards.

On the other hand, it is also possible that low productivity firms chose to be under licensing even though there are constraints. This is because a license to produce was permanent and entry into an industry was not governed by market conditions. Thus there would be a high chance of a low productivity firm surviving and even making super-normal profits without inducing entry from competitors. In this case, treated firms in our sample are systematically low productivity and this will bias our estimates downwards.

Another story we can think of is that firms with low managerial ability chose to be under licensing since they know they will not be able to compete in a more competitive environment. Again, if we are not able to control for these firm-level effects then our estimates may suffer from omitted variable bias.

Ideally, we would like to verify that the results reported above are robust to the inclusion of firm-level fixed effects. That is, we would require information on firm identity and the ability to follow a firm over time. In our data we can theoretically identify 200,000 observations over time (those belonging to the census sector). However, we have not been provided with firm identity numbers by the ASI. But we do have rich data on a variety of firm identifiers and we try to use those data to construct a firm identity number.

We use information on 6 firm-level identifiers:

1. Four-digit industry of production;

2. State where firm is located;

3. Whether located in rural, urban or metropolitan area;

4. The year that the firm started production;

5. The ownership structure of the firm (government owned, wholly privately owned or joint sector) 


\section{The area in which a firm is located.}

There are other firm-level identifiers that could be used like the organization structure of the firm (proprietorship, co-operative society, private corporation etc) and a finer division of the ownership structure (whether owned by the state or central government). However we do not use these since they might change over time for a given firm. Thus, it is possible that a firms organization changes over time from a joint family proprietorship to a private limited company or that a wholly central government owned firm becomes a joint partnership with the state government. However, it is unlikely that a government owned firm (either state or central government) will change to a wholly private firm over time.

The six variables that we have chosen are available for 198,942 observations. Note that our sample of 200,000 observations also includes firms that were closed during the accounting year. We cannot use these firms in our estimation since output and employment figures are not available however we include closed firms while creating the firm-level identifier. This means that the same identifying number is assigned to a firm that is in the data and producing in year $t$, is closed for production in year $t+1$ but enters production again in year $t+2$.

Using these identifiers, we are able to uniquely identify approximately 33,207 firms. For the other firms, there are multiple identity numbers within each year and we drop those firms. Further note that each of these firms does not exist every year. That is, we have only surviving firms in our sample. Our total sample size is 140,562 including closed firms and 100,000 excluding closed firms.

We are still concerned whether we are capturing the same firm over time. It may be that another firm with very similar characteristics existed in the same region and in later years we are capturing that firm. To check for this we use two pieces of information from our data set- the opening and closing stock of fixed capital owned by the firm. Suppose that firm 1 ended year 1980 with Rs. 1 million of capital stock. Then we check whether the firm identified as 1 in 1981 started with capital stock close to Rs. 1 million. This cross-check supports our firm identifier.

Our main concern is that this may not be a random sample. So we provide some descriptive statistics of our panel of firms as compared to all factories. Figure 4 shows the distribution of productivity in exempt and not exempt firms for the pseudo-panel and the full sample firms. The black solid line represents unique firms while the red dashed line represents the all firms. As we can see that the distribution of productivity is very similar for both types of firms over exemption status. 
Any difference between unique firms and all factories are constant over exemption status and hence will get canceled out. For example, the sample of unique firms has higher productivity for both types of firms-exempt and not exempt from licensing requirements. In Figure 5 we investigate the distribution of assets (in plant, machinery, land, building) for exempt firm over de-licensing reform in the full sample and in the pseudo-panel. Within each graph the solid line represents the year 1988 while the dashed line represents the year 1983. Comparing this graph to Figure 1 (that was drawn for the full sample) we can see that the behavior of exempt firms over licensing reform and over time is the same for the full sample as for the pseudo-panel.

The results of the estimation of Equation 2 on uniquely identified firms are presented in Column 1 of Table 7 . We estimate a within-firm regression with year dummies and standard errors clustered around 4 digit industry. The coefficient on the interaction of exemption status with de-licensing is positive and significant at the 5\% level. That is, firms that were treated with de-licensing reform (they were not exempt from licensing and were in industries that were de-licensed) performed $5.7 \%$ better on average than non-treated firms, conditional on firm-level factors (the total impact of deregulation on not exempt firms is $\beta_{1}+\beta_{3}$ ). In Column 2 of Table 7 we include 2-digit industryyear fixed effects to capture different growth paths of different industries and we find that similar to our baseline results, the coefficient on the interaction term is lower in magnitude. The average treated firm did $7.7 \%$ better than a non-treated firm, even after controlling for firm-specific factors and for industry-year interactions. In Column 3 of the table we present the results for the year 1980-90. The coefficient on the interaction if 0.079 and is significant at the $10 \%$ level. That is, after controlling for firm-specific factors, we find that the reforms of the 1980s had a positive and significant impact on the firms that were affected by these reforms.

\section{The Relationship between Trade and Industrial Reforms}

\subsection{Does Deregulation Matter?}

As mentioned earlier, one important feature of the Indian case is the interesting chronology of reforms. In the 1980s, policy was geared towards de-regulating industry to reduce administrative burden as well as unnecessary checks on firm-level decision making. There was little interest in trade reforms and the changes in trade policy that occurred were primarily of the nature of streamlining of the system, rationalization of administrative procedures etc. It was only in 1991, under pressure from international organizations, that the first steps were taken towards trade reforms. 
Following the industrial policy statement of August 1991, there were across-the-board tariff cuts bring down the average un-weighted tariff to $60 \%{ }^{21}$.

Given this chronology of events an important question that arises is what happened to the industries that were deregulated in the 1980s post-trade reform? In this section we will try to assess the impact of the 1991 changes in industrial and trade policies on firm-level productivity.

In Column 1 of Table 8 we present a simple estimate of the post-1991 performance of firms in industries that were de-licensed in the 1980s .

$$
D 80_{j t}= \begin{cases}1 & \text { if industry } j \text { was de-regulated in year } s \leq t \text { of the 1980s } \\ 0 & \text { otherwise }\end{cases}
$$

That is, the $D 80_{j t}$ variable is the same as the $D e_{j t}$ variable. We simply don't include the industries that were deregulated in 1991 and 1993. Our estimation equation is

$$
\begin{aligned}
y_{i j t s}= & \delta_{0}+\delta_{t}+\gamma_{j}+\beta_{0} D 80_{j t}+\beta_{1} \text { NotExempt }{ }_{i t}+\beta_{2}{\text { Post } 91_{t}} \\
& +\beta_{3} \text { D80 }{ }_{j} \text { NotExempt }{ }_{i t}+\beta_{4} \text { D80 }{ }_{j} \text { NotExempt } \text { Post }_{i t} 91_{t} \\
& +\beta_{5} \text { D80 }_{j} \text { Post } 91_{t}+\eta X_{j t s}+\varepsilon_{j t s}
\end{aligned}
$$

The coefficients $\beta_{0}, \beta_{1}$ and $\beta_{3}$ have the same interpretations as in Equation 2. The coefficient on NotExempt ${ }_{i t} D 80_{j t}$ is the impact of de-licensing on the firms that were affected by it . The coefficient $\beta_{4}$ then measures impact of deregulation (conducted in the 1980s) on the affected population of firms in the post-trade reform period (Post-1991). Column 1 of Table 8 shows that this estimate is positive and significant. That is, the average productivity of affected firms (not exempt from licensing and in de-licensed industries) in the post-trade reform period was $8.4 \%$ higher than that of firms that were not deregulated during the 1980s. To get a sense of the impact of deregulation and trade relative to general macroeconomic trends we also present the coefficients on the year dummies below Table 8 . In the second column of the table, we include the variable $D 80_{j} * \operatorname{Post} 91_{t}$. We are worried that without this term, the coefficient on Notexempt ${ }_{i t} D 80_{j} P_{0 s t} 91_{t}$ might be capturing differential trends in productivity in de-licensed industries, post 1991. As Column 2 shows, the coefficient $\beta_{4}$ declines in magnitude after we control for this and significant at the $16 \%$ level $^{22}$.

In Column 3 of Table 8, we check the robustness of our results by running within-firm regressions using our pseudo-panel. Note that even after controlling for $D 80_{j} P o s t 91_{t}$, there is $13 \%$ higher

\footnotetext{
${ }^{21}$ The strength of pre-reform trade barriers and hence the scope of the reforms can be gauged from the fact that according to Panagariya (2004), in 1990-91 the highest tariff rate stood at 355\%, the simple average of all tariffs at $113 \%$ and the import-weighted average of tariff rates at $87 \%$.

${ }^{22}$ We do not include an interaction of Not Exempt ${ }_{i t}$ and Post $91_{t}$ since size-based exemption of firms from licensing provisions was no longer a government policy after the reforms of 1991.
} 
productivity for firms that were deregulated in the 1980s, in the post-1991 period. This confirms our main result that firms that were affected by de-licensing during the 1980s performed better than other firms in the post-1991 period. This points towards a complementarity relationship between trade and industrial policy. That is, a rise in domestic competition raises the marginal response to a trade reform episode.

To assess the immediate and medium-term impact of trade reforms, in Column 4 of Table 8 we split the post-trade reform period into two subperiods. We define Trade $1=1$ if year is 1991 or 1992, 0 otherwise, and Trade $2=1$ if year is 1993 or 1994, 0 otherwise, and interact NotExempt ${ }_{i t} D 80_{j t}$ with both of these variables. As we can see from Table 8 , the immediate short-term impact of the trade reforms was higher productivity for firms that were affected by de-licensing during the 1980 s while the medium term impact is insignificant. As we get more firm-level data for the post-1991 period, we might be able to draw firmer conclusion about the short-, medium- and long-term impact of these reforms.

\subsection{Testing Predictions from Theory}

Our theoretical model (Sharma (2005)) postulates a two-step relationship between trade and industrial policies and the innovation incentives of the firm. The first is the link between trade policy and innovation incentives. The second is the link between industrial policy (deregulation) and the response of innovation to trade reform.

The link between trade policy and innovation incentives is mediated by the technological status of the industry. Specifically, trade liberalization encourages innovation in industries that are more advanced technologically and discourages innovation in other industries. The intuition for this result is that not-so-advanced industries know that they will not be able to compete with foreign firms (assumed to be very advanced) and would prefer to cut their losses by not investing in technology. On the other hand, advanced industries realize that they have a good chance of deterring entry by foreign competitors if they invest in technology and manage to become productive enough to deter entry by foreign firms.

The second link is that between industrial policy and innovation. Our theory postulates that there is a relationship between trade and industrial policies vis their effect on a firm's incentives to invest in innovation. That is, under certain conditions ${ }^{23}$ an industry that faces more domestic

\footnotetext{
${ }^{23}$ The condition is that there is a high degree of monopolistic distortion prior to industrial deregulation. That is, the price-cost margin of the industry is above a certain level. This condition will be true for industries that were subject
} 
competition will have a higher marginal response to the higher threat of entry following a trade liberalization episode. A technologically advanced industry will raise its investment in productivity in response to a more competition from abroad, but this response will be higher when he faces more competition at home.

This strategic complementarity relationship means that productivity will be higher in industries that are initially more competitive (in the case of India, due to industrial deregulation that removed barriers to entry into industry) and now face a higher threat of entry from foreign competitors. Further given the relationship between the technological nature of the industry (advanced or backward) and trade reform, this positive relationship between industrial deregulation and trade reform rises as the industry becomes more advanced i.e. improves in technology. This translates into a prediction of higher productivity in industries that were deregulated in the 1980s and had higher productivity (i.e. were more advanced), in the post-1991 period.

There are two points to note about our result. The first is that we do not explicitly model trade. That is, the trade reform is modeled as a rise in the threat of entry from foreign competitors and advanced industries react by competing while backward industries by retreating. That is, the only impact of trade that we are interested in comes through the resultant increase in competition. The second point to notice is that in our case, industrial deregulation was followed by a rise in competition due to a trade reform episode.

Thus, an interesting test of our predictions from the theory is the following. Do industries that were affected by the first rise in competition during the 1980s and were technologically advanced as a result of that, become more productive after the second rise in competition during the 1990s?

We try a direct test of our theoretical prediction by analyzing the performance of firms in industries that were deregulated in the 1980s, in the period after 1991. Note that de-licensing in the 1980s occurred in the years 1984, 1985, 1986 and 1987. So the period 1988-1990 can be used to measure the medium-term impact of de-licensing in the absence of trade reform. The period 1991-94 can be used to measure the immediate impact of the trade reform episode.

Now we include a variable to indicate the technological status of an industry. We define the technological status of an industry based on its performance in the years 1983 and 1988. We define

$$
\text { Initial }_{j}= \begin{cases}1 & \text { industry } \mathrm{j} \text { has higher productivity in } 1988 \text { compared to } 1983 \\ 0 & \text { otherwise }\end{cases}
$$

to industrial licensing since by default, entry into the industry was determined exogenously and was not a result of market forces. 
Our regression equation, which we estimate for the period 1988-94, is given below

$$
\begin{array}{r}
y_{i j t s}=\beta_{0}+\delta_{t}+\zeta_{j}+\gamma_{0} \text { Initial }_{j} \text { Post }_{91_{t}}+\gamma_{1} \text { D80 } 0_{j}+\gamma_{2} \text { D80 }{ }_{j}{\text { Post } 91_{t}} \\
+\gamma_{3} \text { D80 } \text { Intial }_{j} \text { Post } 91_{t}+\eta X_{i j t s}+\varepsilon_{i j t s}
\end{array}
$$

Here $y_{i j t s}$ is the productivity of firm $\mathrm{i}$ industry $\mathrm{j}$ at time $\mathrm{t}$, located in state $\mathrm{s}$. The coefficient on Initial $_{j}$ Post $91_{t}$ is a test of our prediction that technologically advanced industries perform better after a trade reform episode. The coefficient on $D 80_{j}$ Intial $_{j}$ Post $91_{t}$ is a test of our prediction that the marginal response to trade reform rises as the industry faces more competition domestically. Thus $\gamma_{3}>0$ will confirm our prediction that industries respond more aggressively to trade reform if they face more competition domestically ${ }^{24}$. We include $D 80_{j}$ to control for any special features that these industries may have. We include $D 80_{j}$ Post $91_{t}$ to control to allow for heterogenous response to the macroeconomic shock in the deregulated industries.

In Table 10 we present the estimates of this equation for the period 1988-94. In Column 1 we control for 2-digit industry-year effects (to control for time-varying heterogeneity in industry growth paths), state effects and firm-level controls like ownership, organization, location etc. These are within-industry regressions. We use 4-digit industry effects and since $D 80_{j}$ varies at 4-digit industry, $\gamma_{1}$ is not identified. However the coefficient of interest is identified. As Column 1 shows $\gamma_{3}$ is positive and significant. Thus, industries that were de-regulated in the 1980 s and were technologically advanced did better in the period of high competition following trade reform ${ }^{25}$.

An important point to note from Column 1 is that the coefficient on $\gamma_{2}$ is negative and insignificant. That is, industries that were deregulated during the 1980s on average performed the same or worse in the post-1991 period. However the impact of $D 80_{j}$ in the post-1991 period is $\gamma_{2}+\gamma_{3} *$ Initial $_{j}$. Thus an advanced industry that was deregulated in the 1980 s had $17.8 \%$ higher productivity on average in the post-1991 period (since $\gamma_{2}$ is not significant).

\footnotetext{
${ }^{24}$ In our definition of the initial productivity status of the industry there is an implicit assumption of spill-overs from deregulation. As mentioned earlier, only Not Exempt firms were under the ambit of licensing and hence were affected by de-licensing. Since we define Initial using the average productivity of an industry, both exempt and non-exempt firms are included in the calculation of Initial. Thus, the implicit assumption is that there were spill-overs from the de-licensing of Not Exempt firms on the productivity of Exempt firms. This could be because Exempt firms were forced to deal with free entry in all types of firms, not just the Exempt ones. This means that industries where the Exempt firms also became more productive after de-licensing are more likely to have done well between 1983 and 1988.

${ }^{25}$ In the context of our discussion of the definition of Initial, this result implies that industries where even the Exempt firms became more productive after de-licensing, raising average industry productivity, did really well after trade reforms. Thus, the impact of trade reforms is enhanced when there are productivity spill-overs to firms that were not affected by de-licensing.
} 
Note that $\gamma_{0}$ is negative. That is, industries that were doing well during the 1980 s performed worse after trade reforms. However, the total impact of trade reforms is $\gamma_{0}+\gamma_{3}$ for advanced industries that were deregulated during the 1980s and this is positive. One possible reason for the negative impact of trade reform on advanced industries could be that there is no notion of comparative advantage in our model and estimation. It is possible that some industries may be technologically advanced prior to trade reform but they collapse after trade reforms since they do not have a comparative advantage in that product. As a caveat, in a differentiated product model such as ours, some goods in all industries could be exported after trade reform unless firm productivity falls too low and it cannot can not overcome a trading cost.

In Column 2 we present results for when we control for 3-digit industry rather than 4-digit. The purpose of this is to be able to identify the coefficient on $D 80_{j}$. This analysis bears out our basic results. The coefficient $\gamma_{3}$ is positive confirming the strategic complementarity relationship between trade and industrial policy. The total impact of deregulation during the 1980s was to raise the post-1991 productivity of those industries $\left(\gamma_{1}+\gamma_{2}\right)$ by $6.6 \%$.

It is interesting to note that our results are very similar to the ones presented here when we try a very different measure of whether the firm is advanced of not. Rather than comparing intertemporal advance in the technical status of the industry, we compare average productivity of each industry with the maximum productivity in that industry in the year 1988. That is, we take into account not only the highest productivity in an industry but also the dispersion of firms according to productivity, within the industry. And our main result, that industries that are more productive and were deregulated during the 1980s performed better after the reforms of 1991 holds. That is, this very different measure of distance from the technological frontier also provides evidence of the strategic complementarity relationship between trade and industrial policy. However here too we get the puzzling result that industries that are closer to the frontier, perform worse after $1991^{26}$.

Our preliminary and simple tests show that firms in industries that were de-licensed in the

\footnotetext{
${ }^{26} \mathrm{~A}$ possible explanation for this result is a composition effect. Our measure of the technological status of the industry takes in to account average industry productivity and compares it with the maximum industry productivity. Suppose that firms are heterogenous in productivity within an industry and there are fixed and variable costs to exporting (a Melitz (2003) set-up). After trade reforms, firms with the lowest productivity exit (or supply only the domestic market) while the highest productivity firms expand and their labor productivity rises. Keeping in mind our definition of the frontier, in an industry where there are many productive firms, trade reform could lead to a decline in recorded productivity since these firms lose sales to foreign varieties. In an industry with a large dispersion of productivity, the least productive firms exit while the most productive firms expand and record even higher output per worker. Thus industries that are "advanced" see a decline in productivity while the "backward" ones see a rise in productivity. This point again reveals that integrating an explicit trade model into our model might yield interesting and important predictions
} 
1980s and hence faced a more competitive, market-oriented environment in the 1980s performed better after a trade reform episode as compared to firms in industries that were not de-regulated in the 1980s. Thus the strategic complementarity relationship postulated by our theory seems to hold for the case of India. Future work that ties together our theory with a trade model may shed more light on the our model and predictions.

\section{Conclusions and Future Work}

In this paper we use two unique data sets, the institutional features of Indian policy and the interesting chronology of reforms in India to address two issues. The first is whether industrial de-regulation that increases the level of competition that a firm has to face leads affects firm-level productivity. We find the answer to this is affirmative. Confirming our intuition as well as predictions from our theoretical model we find that firms that were affected by de-licensing had higher labor productivity than non-affected firms. Thus more competition spurs firms to perform better. We solve the problem of industry-level omitted variables that may bias our estimates by using the fact that some firms were exempt from licensing. By differencing over these two types of firms we are able to get consistent, unbiased estimates of the impact of reforms.

The second issue that we address is whether there is a relationship between industrial deregulation and trade reform. Given the chronology of reforms in India, what happened to the productivity of the firms that were in industries deregulated during the 1980s after the trade reforms of 1991 ? We find that firms in industries that were de-licensed in the 1980s and had higher productivity as a result of that tended to have higher productivity post-1991.

Our results are robust to the inclusion of a wide variety of firm- and industry-level controls and fixed effects. One implication of using fixed-effect methods to assess the impact of reforms is that we can test an implication of our identification assumption-for the set of industries were exemption from licensing was not available there should be no variation in the performance of firms due to de-licensing around the threshold for licensing-and we find that this assumption holds. In another specification test, we check for the significance of randomly chosen thresholds for licensing and find that only the official threshold matters with respect to differential performance in exempt and not exempt firms. Further we find no evidence of bunching of firms around the threshold for licensing and no evidence of firms choosing their exemption status based on anticipations of delicensing reform. We also construct a panel of firms to test the robustness of our estimates to the 
inclusion of firm fixed effects.

Our results have interesting policy implications. An important one is that domestic competitive environment can be used to prepare firms in the economy for trade reforms. Under competition from high-productivity foreign firms, domestic firms that are not productive may want to cut their losses and not invest in productivity-enhancing technology. However a rise in the level of domestic competition can spur these firms to make investments in technology prior to facing competition from abroad and hence prepare them for an even more competitive environment.

There are several important issues that remain to be answered about the Indian reforms. The first is the debate about unexplained rise in the total factor productivity of Indian manufacturing prior to the reforms of 1991 (Delong (2001), Panagariya (2001), Panagariya (2002), Panagariya (2004)). Our estimates of labor productivity reveal that there was rise in productivity during the 1980s and that this was the result of de-licensing. We can extend this study to other measures of productivity and assess whether total factor productivity rose as a result of de-licensing.

Another issue is that of the mechanism through which de-licensing affected firm productivity. It may be possible to delineate the roles of firm-level incentives to invest in technology as a result of more competition from firm-level ability to invest in technology as a result of de-regulation. Licensing curbed the ability of the firm because many firm-level decisions (location, amount produced etc) were decided by licensing authorities. We have detailed information on these policies and analysis may shed more light on the issue of ability vs. incentives as well as on the role of locational or output constraints.

We can test another prediction from our theoretical model that the productivity is affected by the level of competition in your own sector as well as the level of competition in your upstream sector. The intuition for this result is that a reduction in the monopolistic distortion in the upstream sector raises the bargaining power of the downstream sector, allowing it to recoup more of the surplus from its investment in technology. Thus, even if the downstream industry is not deregulated there should be a rise in its productivity if its principal upstream buyer is deregulated. Using input-output matrices for the 1980s and 1990s we can identify the principle buying sector for each industry and test this prediction.

We also plan to assess the impact of a firm's technological status (as opposed to an industry's technological status) on its response to more competition from abroad. For this, we can use our pseudo-panel of firms to identify those firms that saw an increase in their productivity between 1980 and 1990 and showing that they experience an increase in productivity after 1991 greater 
than the ones that did not see a rise in productivity between 1980 and 1990.

Finally, as mentioned earlier it might be very informative and interesting to try to incorporate a trade model into our simple theoretical framework in order to gain more insight in to the mechanisms through which trade can affect firm-level productivity. 


\section{Tables}

\begin{tabular}{lllll}
\hline & All Output & Factory Output & All Value Added & Factory Value Added \\
\hline 1984 & 7.00 & 7.10 & 10.00 & 10.10 \\
1985 & 18.30 & 20.30 & 27.70 & 29.00 \\
1986 & 3.80 & 3.60 & 3.70 & 3.70 \\
1987 & 26.50 & 27.90 & 32.70 & 32.50 \\
1991 & 59.10 & 58.30 & 56.90 & 56.30 \\
1992 & 0.00 & 0.00 & 0.00 & 0.00 \\
1993 & 2.60 & 2.80 & 3.20 & 3.20 \\
\hline
\end{tabular}

Table 1: Percentage of Output and Value Added De-licensed in each year. Source: Annual Survey of Industries; "Guidelines for Industry", Ministry of Industry (various issues) and own calculations. Note: Factories are defined as enterprizes using power in the production process and 50 or more workers or enterprisers not using power in the production process and 100 or more workers. According to the act under which licensing was promulgated in India, these factories were the ones under licensing.

\begin{tabular}{llll}
\hline Year & \multicolumn{3}{|c}{ Inverse of Sampling Probability } \\
\hline & 1 & 2 & 3 \\
\hline 1980 & 13,345 & 2,880 & 0 \\
1981 & 13,746 & 2,910 & 0 \\
1982 & 14,771 & 2,913 & 0 \\
1983 & 13,883 & 2,319 & 0 \\
1984 & 13,398 & 2,240 & 0 \\
1985 & 13,785 & 2,439 & 0 \\
1986 & 13,747 & 2,236 & 0 \\
1987 & 11,080 & 2 & 2,786 \\
1988 & 11,183 & 1 & 2,804 \\
1989 & 11,195 & 186 & 2,880 \\
1990 & 10,894 & 321 & 2,801 \\
1991 & 11,202 & 353 & 2,752 \\
1992 & 11,739 & 289 & 3,183 \\
1993 & 11,915 & 312 & 3,413 \\
1994 & 12,607 & 349 & 3,380 \\
\hline
\end{tabular}

Table 2: Characteristics of the data 


\begin{tabular}{lcl}
\hline Variable & Mean & Std. Dev. \\
\hline \multicolumn{1}{c}{ Not Exempt Firms (Observations=12825) } \\
\hline Ln (Output per Worker) & 8.6 & 1.113734 \\
Real Output (1993-94 Rs.) & $1.25 \mathrm{E}+07$ & $2.95 \mathrm{E}+07$ \\
Book value of Assets in & $4.45 \mathrm{E}+08$ & $1.98 \mathrm{E}+09$ \\
Plant, machinery, land and building (Rs.) & 1814.088 & 3369.832 \\
\hline \multicolumn{3}{c}{ Employees } \\
\hline \multicolumn{3}{c}{ Exempt Firms (Observations=286567) } \\
\hline Ln (Output per worker) & 7.22921 & 1.452706 \\
Real Output (1993-94 Rs.) & 591649.6 & 1333756 \\
Book value of Assets in & 6612464 & $1.53 \mathrm{E}+07$ \\
Plant, machinery, land and building (Rs.) & & \\
Employees & 219.8095 & 683.028 \\
\hline
\end{tabular}

Table 3: Summary Statistics for All Factories. Factories are defined as enterprizes using power in the production process and 50 or more workers or enterprizes not using power in the production process and 100 or more workers. According to the act under which licensing was promulgated in India, these factories were the ones under licensing. Not exempt firms are those that were under licensing, exempt firms are those that were granted an exemption from licensing based on the size of their assets.

\begin{tabular}{|c|c|c|c|}
\hline & \multicolumn{3}{|c|}{ Exempt Firms in Licensed Industries } \\
\hline & Mean & Median & $75^{\text {th }}$ Percentile \\
\hline 1980s & 16.99 & 17.13 & 17.77 \\
\hline $1980-83$ & 26.26 & 29.73 & 23.81 \\
\hline \multirow[t]{3}{*}{ 1984-89 } & 6.70 & 11.52 & 12.97 \\
\hline & \multicolumn{3}{|c|}{ Exempt Firms in De-licensed Industrie } \\
\hline & Mean & Median & $75^{\text {th }}$ Percentile \\
\hline 1980s & 15.45 & 14.09 & 15.96 \\
\hline $1980-83$ & 20.04 & 16.96 & 19.39 \\
\hline 1984-89 & 7.05 & 10.88 & 10.53 \\
\hline
\end{tabular}

Table 4: Average Annual Rates of Growth of Assets(\%). Schedule IV and V industries are not included here. Assets refers to the book value of assets in plant, machinery, land and building. 
Note: For Tables 5 to 10 , *** refers to significance at the $1 \%$ level, ** to $5 \%$ and $*$ to $10 \%$ level. Controls are ownership, organization, location of the firm, whether large firms were allowed to enter the industry, wage to rental ratio. The dependant variable is $\log$ (Output per worker). Each observation is weighted by its sampling probability. NotExempt ${ }_{i t}=1$ if firm was under licensing requirements, $D e_{j t}=1$ if industry was de-licensed in year t. For all regressions standard errors are clustered around 4-digit industry.

\begin{tabular}{lllll}
\hline & Baseline & $\begin{array}{l}\text { Baseline } \\
1980-90\end{array}$ & Industry-trend & $\begin{array}{l}\text { Industry-trend } \\
1980-90\end{array}$ \\
\hline NotExempt & $0.593 * * *$ & $0.587 * * *$ & $0.607 * * *$ & $0.598 * * *$ \\
& {$[0.100]$} & {$[0.096]$} & {$[0.096]$} & {$[0.096]$} \\
De & $-0.055^{* * *}$ & $-0.093 * *$ & $-0.064 * *$ & $-0.067 * *$ \\
& {$[0.021]$} & {$[0.042]$} & {$[0.020]$} & {$[0.033]$} \\
De*NotExempt & $0.161 * *$ & 0.148 & $0.132 *$ & 0.102 \\
& {$[0.078]$} & {$[0.112]$} & {$[0.073]$} & {$[0.114]$} \\
Constant & $6.252 * * *$ & $6.428 * * *$ & $6.187 * * *$ & $6.412 * * *$ \\
& {$[0.150]$} & {$[0.209]$} & {$[0.134]$} & {$[0.170]$} \\
Observations & 172297 & 125898 & 172297 & 125898 \\
R-squared & 0.51 & 0.52 & 0.51 & 0.53 \\
\hline Industry-Trend & No & No & Yes & Yes \\
(3-digit) & & & & \\
Industry FE & Yes & Yes & Yes & Yes \\
(4-digit) & & & & \\
State FE & Yes & Yes & Yes & Yes \\
Year FE & Yes & Yes & Yes & Yes \\
\hline
\end{tabular}

Table 5: Baseline Results. These regressions do not include Schedule IV and Schedule V industries. 


\begin{tabular}{lllll}
\hline & $\begin{array}{l}\text { Ind-Year } \\
\text { Effects }\end{array}$ & $\begin{array}{l}\text { Ind-Year } \\
1980-90\end{array}$ & Winsorised & $\begin{array}{l}\text { Ind-State } \\
\text {-Year Effects }\end{array}$ \\
\hline NotExempt & $0.612^{* * *}$ & $0.595^{* * *}$ & $0.590^{* * *}$ & $0.673^{* * *}$ \\
& {$[0.097]$} & {$[0.098]$} & {$[0.093]$} & {$[0.022]$} \\
De & -0.008 & -0.015 & -0.01 & $0.338^{*} * *$ \\
& {$[0.024]$} & {$[0.029]$} & {$[0.023]$} & {$[0.037]$} \\
De*NotExempt & $0.128^{*}$ & 0.128 & $0.113 *$ & $0.094 * * *$ \\
& {$[0.070]$} & {$[0.109]$} & {$[0.067]$} & {$[0.032]$} \\
Constant & $6.260 * * *$ & $6.608 * * *$ & $6.270 * * *$ & $6.415^{*} * *$ \\
& {$[0.148]$} & {$[0.220]$} & {$[0.153]$} & {$[0.037]$} \\
Observations & 172297 & 115357 & 172297 & 172297 \\
R-squared & 0.51 & 0.53 & 0.52 & 0.62 \\
\hline Industry-Year & Yes & Yes & Yes & No \\
(2-digit) & & & & \\
Ind-State-Year Effects & No & No & No & Yes \\
Industry FE & Industry FE & Yes & Yes & Yes \\
(4-digit) & $(4-d i g i t)$ & & & \\
State FE & State FE & Yes & Yes & Yes \\
Year FE & Year FE & Yes & Yes & Yes \\
\hline
\end{tabular}

Table 6: Robustness Checks. These regressions do not include Schedule IV and V industries.

\begin{tabular}{llll}
\hline & Base & $\begin{array}{l}\text { Industry-Year } \\
\text { Effects }\end{array}$ & $1980-90$ \\
\hline NotExempt=1 & 1 & 2 & 3 \\
\hline De=1 & $0.126^{* * *}$ & $0.141^{* * *}$ & $0.109 * * *$ \\
& {$[0.032]$} & {$[0.033]$} & {$[0.036]$} \\
De*NotExempt & $-0.048^{* *}$ & -0.03 & -0.0405 \\
& {$[0.024]$} & {$[0.026]$} & {$[0.034]$} \\
Constant & $0.105^{* *}$ & $0.077 *$ & $0.079 *$ \\
& {$[0.044]$} & {$[0.040]$} & {$[0.048]$} \\
Observations & $7.323^{* * *}$ & $7.370^{* * *}$ & $6.81 * * *$ \\
R-squared & {$[0.053]$} & {$[0.072]$} & {$[0.071]$} \\
\hline Number of group(id23) & 93714 & 94714 & 68348 \\
Industry Effects & 0.05 & 0.07 & 0.06 \\
State Effects & Yes & 33207 & 26065 \\
Year Effects & Yes & Yes & Yes \\
Industry-Year Effects & Yes & Yes & Yes \\
\hline
\end{tabular}

Table 7: Results for Pseudo-Panel of firms. These are within-firm regressions. In columns 2 and 3 we include 2-digit industry effects interacted with year effects. 


\begin{tabular}{|c|c|c|c|c|}
\hline & Baseline & $\begin{array}{l}\text { Baseline } \\
\text { Robust }\end{array}$ & Pseudo-Panel & $\begin{array}{l}\text { Medium \& } \\
\text { Short run }\end{array}$ \\
\hline \multirow[t]{2}{*}{ NotExempt } & $0.644 * * *$ & $0.644 * * *$ & $0.150 * * *$ & $0.644 * * *$ \\
\hline & {$[0.094]$} & [0.094] & {$[0.027]$} & {$[0.094]$} \\
\hline \multirow[t]{2}{*}{ D80 } & 0.027 & 0.013 & $-0.082 * * *$ & 0.027 \\
\hline & {$[0.032]$} & {$[0.030]$} & {$[0.031]$} & {$[0.032]$} \\
\hline \multirow[t]{2}{*}{$\mathrm{NE}^{*} \mathrm{D} 80$} & 0.058 & 0.066 & 0.054 & 0.058 \\
\hline & [0.112] & [0.112] & {$[0.035]$} & [0.112] \\
\hline \multirow[t]{2}{*}{ NE*D80*Post91 } & $0.084 *$ & $0.067^{\dagger}$ & $0.137 * * *$ & \\
\hline & {$[0.046]$} & [0.048] & {$[0.045]$} & \\
\hline \multirow[t]{2}{*}{ D80*Post91 } & & 0.038 & -0.002 & \\
\hline & & {$[0.035]$} & {$[0.041]$} & \\
\hline \multirow[t]{2}{*}{ NE*D80*Trade 1} & & & & $0.141 * * *$ \\
\hline & & & & {$[0.046]$} \\
\hline \multirow[t]{2}{*}{ NE*D80*Trade 2} & & & & 0.042 \\
\hline & & & & {$[0.058]$} \\
\hline \multirow[t]{2}{*}{ Post91 } & $0.788 * * *$ & $0.784 * * *$ & $0.426 * * *$ & \\
\hline & {$[0.126]$} & {$[0.128]$} & {$[0.035]$} & \\
\hline \multirow[t]{2}{*}{ Trade1 } & & & & $0.856 * * *$ \\
\hline & & & & {$[0.118]$} \\
\hline \multirow[t]{2}{*}{ Trade2 } & & & & $1.053 * * *$ \\
\hline & & & & {$[0.141]$} \\
\hline \multirow[t]{2}{*}{ Constant } & $6.259 * * *$ & $6.258 * * *$ & $7.210 * * *$ & $6.258 * * *$ \\
\hline & {$[0.148]$} & {$[0.148]$} & {$[0.020]$} & {$[0.148]$} \\
\hline \multirow[t]{2}{*}{ Observations } & 172297 & 172297 & 95639 & 172297 \\
\hline & 0.51 & 0.51 & 0.04 & 0.51 \\
\hline \multicolumn{5}{|l|}{ 2-digit Industry- } \\
\hline Year effects & Yes & Yes & Yes & Yes \\
\hline Industry Effects & 4-digit & 4-digit & 4-digit & 4-digit \\
\hline State Effects & Yes & Yes & Yes & Yes \\
\hline
\end{tabular}

Table 8: Impact of Trade Reforms. These regressions do not include Special industries. $\dagger$ represents significance at the $16 \%$ level. 


\begin{tabular}{|c|c|c|c|c|}
\hline & Baseline & $\begin{array}{l}\text { Baseline } \\
\text { Robust }\end{array}$ & Pseudo-Panel & $\begin{array}{l}\text { Medium \& } \\
\text { Short run }\end{array}$ \\
\hline \multirow[t]{2}{*}{1981} & $0.126^{* * *}$ & $0.126^{* * *}$ & $0.050 * * *$ & $0.126 * * *$ \\
\hline & {$[0.035]$} & {$[0.035]$} & {$[0.016]$} & {$[0.035]$} \\
\hline \multirow[t]{2}{*}{1982} & $0.096 * *$ & $0.096 * *$ & $0.050 * * *$ & $0.096 * *$ \\
\hline & {$[0.042]$} & {$[0.042]$} & {$[0.015]$} & {$[0.042]$} \\
\hline \multirow[t]{2}{*}{1983} & $0.194 * * *$ & $0.194 * * *$ & $0.076 * * *$ & $0.194 * * *$ \\
\hline & {$[0.050]$} & {$[0.050]$} & {$[0.023]$} & {$[0.050]$} \\
\hline \multirow[t]{2}{*}{1984} & $0.442 * * *$ & $0.443 * * *$ & $0.135 * * *$ & $0.442 * * *$ \\
\hline & [0.093] & [0.092] & {$[0.024]$} & {$[0.093]$} \\
\hline \multirow[t]{2}{*}{1985} & $0.562 * * *$ & $0.564 * * *$ & $0.233 * * *$ & $0.562 * * *$ \\
\hline & [0.098] & [0.097] & {$[0.034]$} & [0.098] \\
\hline \multirow[t]{2}{*}{1986} & $0.595 * * *$ & $0.597 * * *$ & $0.254 * * *$ & $0.595 * * *$ \\
\hline & {$[0.113]$} & {$[0.111]$} & {$[0.031]$} & {$[0.113]$} \\
\hline \multirow[t]{2}{*}{1987} & $0.582 * * *$ & $0.585 * * *$ & $0.250 * * *$ & $0.582 * * *$ \\
\hline & {$[0.106]$} & {$[0.104]$} & {$[0.029]$} & {$[0.106]$} \\
\hline \multirow[t]{2}{*}{1988} & $0.737 * * *$ & $0.740 * * *$ & $0.315 * * *$ & $0.737 * * *$ \\
\hline & {$[0.132]$} & {$[0.131]$} & {$[0.031]$} & {$[0.132]$} \\
\hline \multirow[t]{2}{*}{1989} & $0.784 * * *$ & $0.787 * * *$ & $0.405 * * *$ & $0.784 * * *$ \\
\hline & {$[0.116]$} & {$[0.114]$} & {$[0.032]$} & {$[0.116]$} \\
\hline \multirow[t]{2}{*}{1990} & $0.710 * * *$ & $0.712 * * *$ & $0.455 * * *$ & $0.710 * * *$ \\
\hline & {$[0.078]$} & [0.077] & [0.029] & {$[0.078]$} \\
\hline \multirow[t]{2}{*}{1991} & $0.068 * *$ & $0.068 * *$ & 0.029 & $0.068 * *$ \\
\hline & [0.032] & {$[0.032]$} & [0.026] & [0.033] \\
\hline \multirow[t]{2}{*}{1992} & $0.070 * *$ & $0.054 * *$ & -0.022 & $-0.068 * *$ \\
\hline & {$[0.031]$} & {$[0.030]$} & {$[0.020]$} & {$[0.032]$} \\
\hline \multirow[t]{2}{*}{1993} & $0.074 * *$ & $0.074 * *$ & -0.027 & $-0.190 * * *$ \\
\hline & {$[0.030]$} & [0.029] & {$[0.017]$} & {$[0.032]$} \\
\hline \multirow[t]{2}{*}{1994} & $0.265 * * *$ & $0.264 * * *$ & 0.029 & $0.068 * *$ \\
\hline & {$[0.052]$} & {$[0.052]$} & {$[0.026]$} & {$[0.034]$} \\
\hline
\end{tabular}

Table 9: Year Effects in Trade Regression 


\begin{tabular}{lll}
\hline & Within 4-digit industry & Within 3-digit industry \\
\hline Initial*Post91*D80 & $0.178^{* *}$ & $0.511^{* * *}$ \\
& {$[0.074]$} & {$[0.121]$} \\
Initial*Post91 & $-0.084^{* *}$ & $-0.161^{* *}$ \\
& {$[0.042]$} & {$[0.063]$} \\
D80 & & $0.477 * * *$ \\
& & {$[0.156]$} \\
D80*Post91 & -0.113 & $-0.411^{* * *}$ \\
& {$[0.071]$} & {$[0.110]$} \\
Constant & $6.567 * * *$ & $6.546^{* * *}$ \\
& {$[0.202]$} & {$[0.199]$} \\
Observations & 75476 & 75476 \\
R-squared & 0.46 & 0.44 \\
\hline 2-digit Industry Year effects & Yes & Yes \\
Industry Effects & $4-$ digit & 3 -digit \\
State Effects & Yes & Yes \\
Year Effects & Yes & Yes \\
\hline
\end{tabular}

Table 10: Impact of Trade Reforms on Advanced Industries. These regressions do not include Special industries.

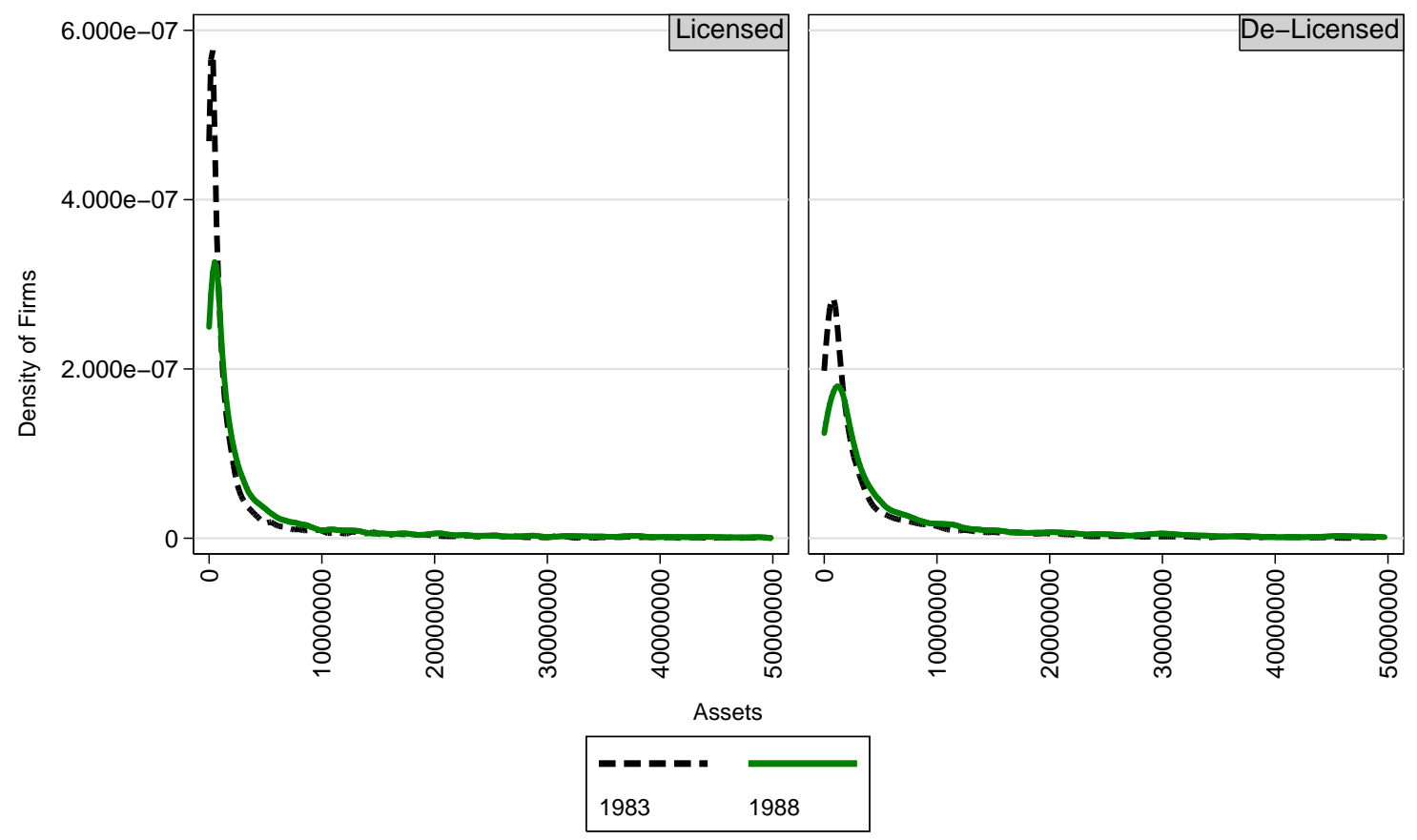

Figure 1: Distribution of Assets of Exempt firms: Assets $<=$ Rs.50 million. 


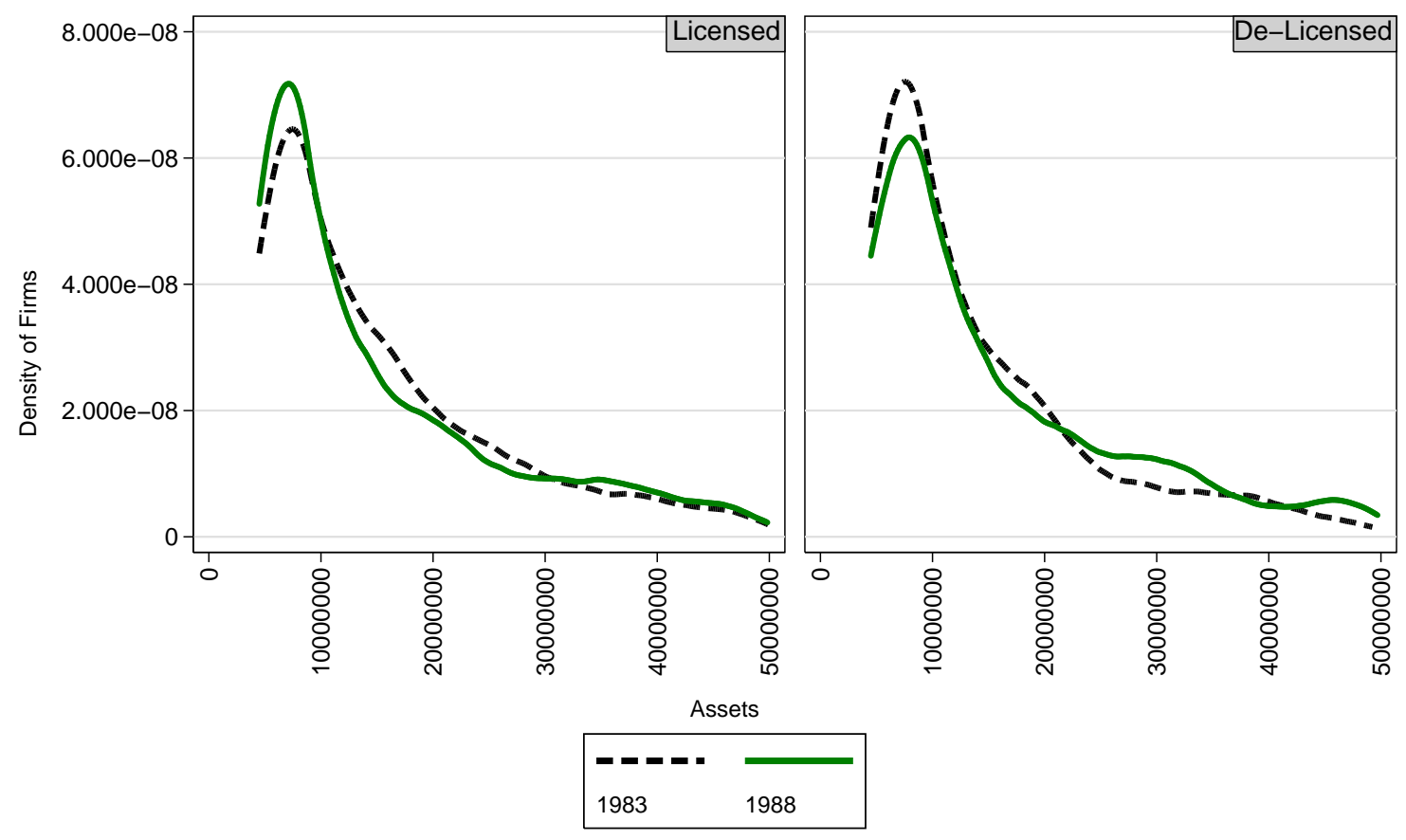

Figure 2: Distribution of Assets of Exempt firms: Rs.50 million=>Assets $>$ Rs.4.5 million.

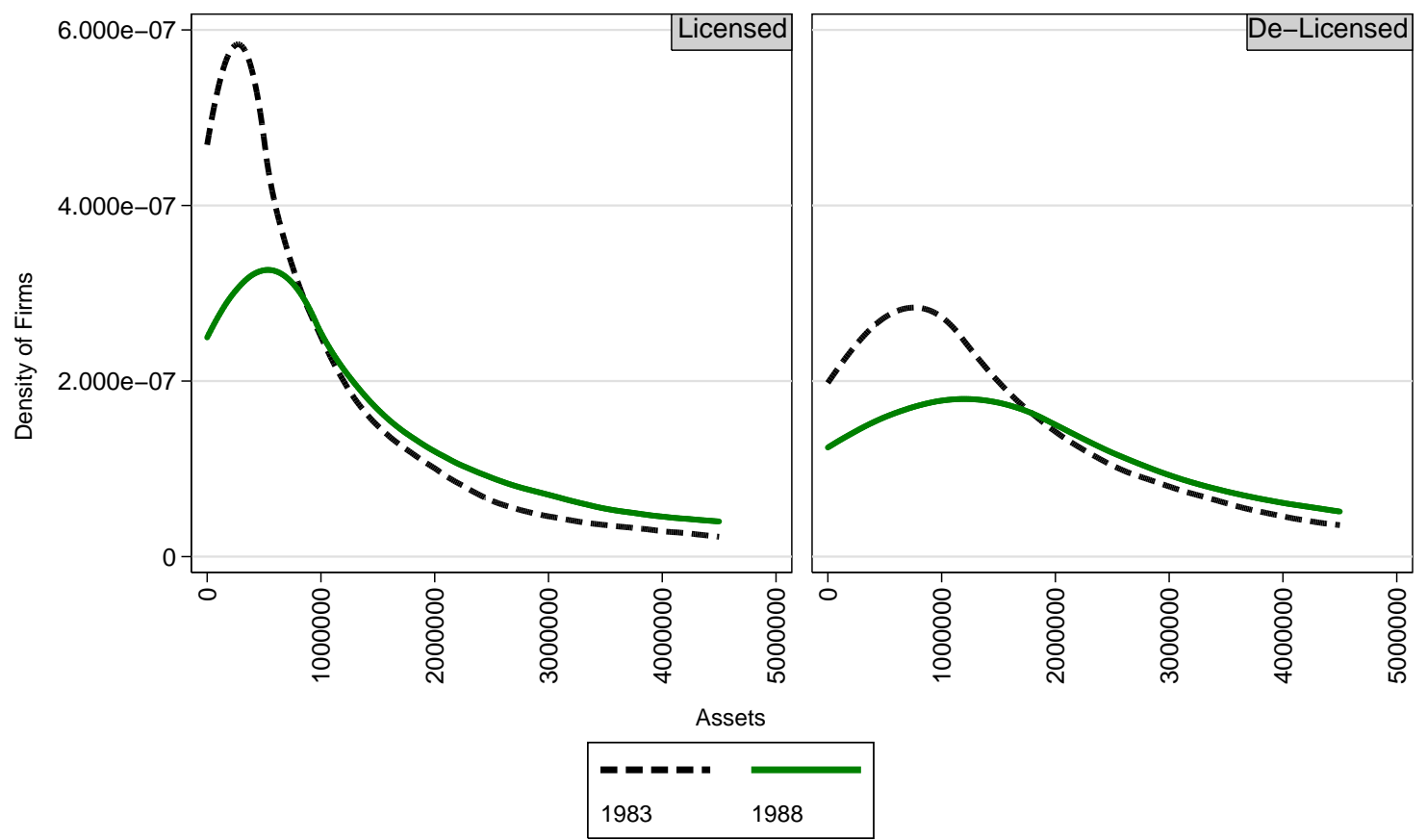

Figure 3: Distribution of Assets of Exempt firms: Assets $<=$ Rs.4.5 million. 


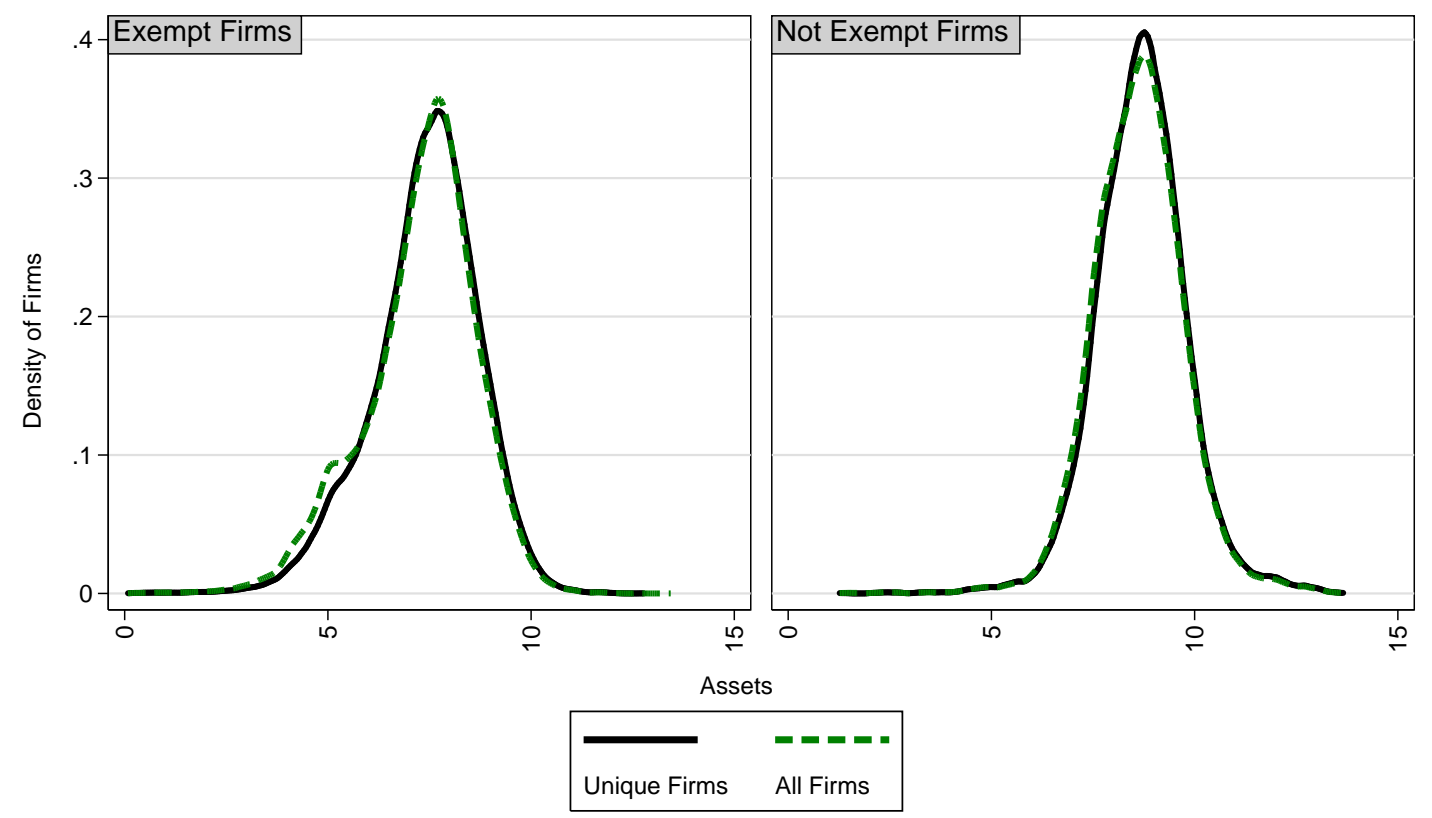

Figure 4: Distribution of Productivity in the Pseudo-panel. The solid line represents the distribution of unique firms-those that were assigned a firm id number. The dashed line represents all firms.

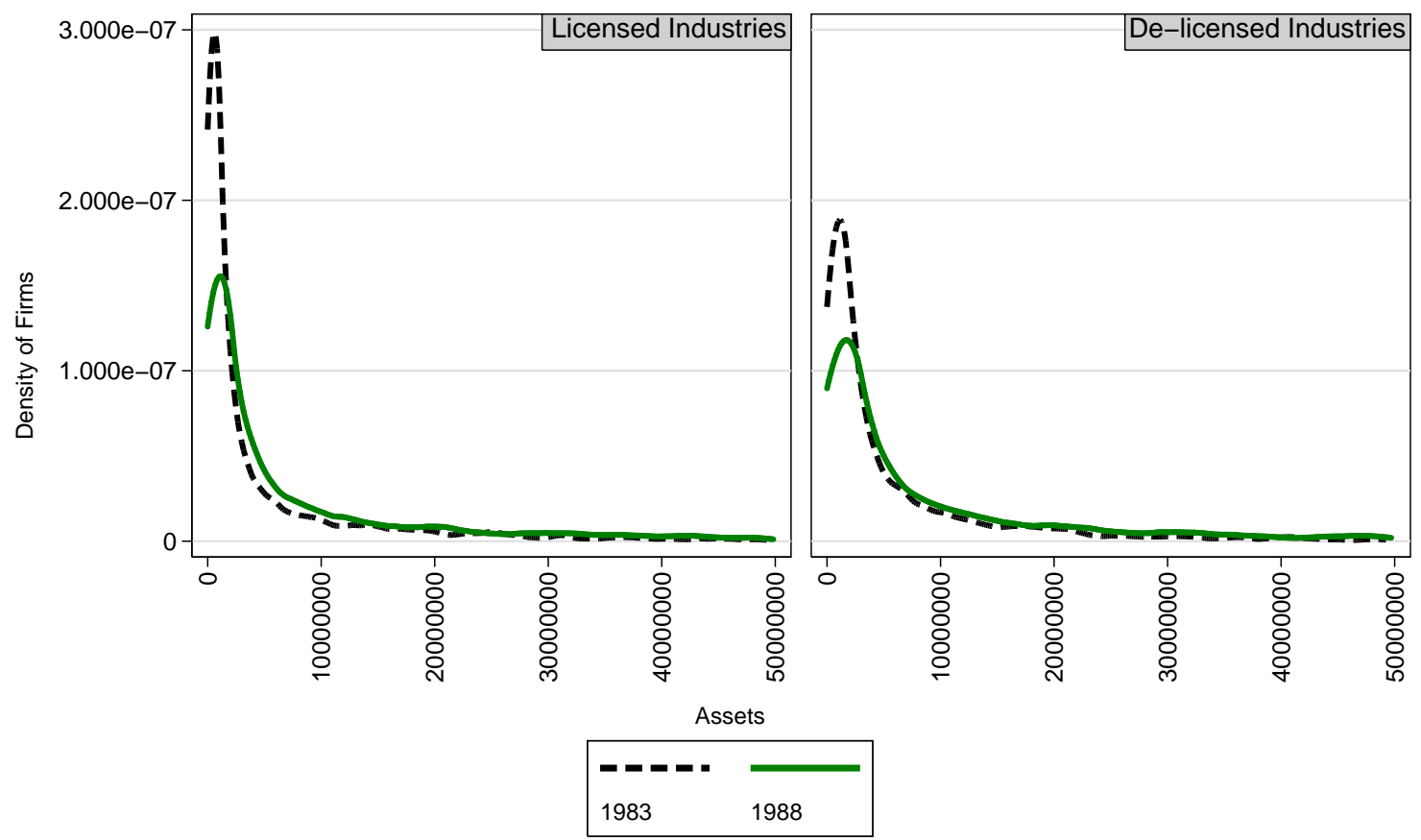

Figure 5: Distribution of Assets of Exempt Firms in the Pseudo-panel. The dashed line represents the distribution of unique firms in 1983, the solid line in 1988. 


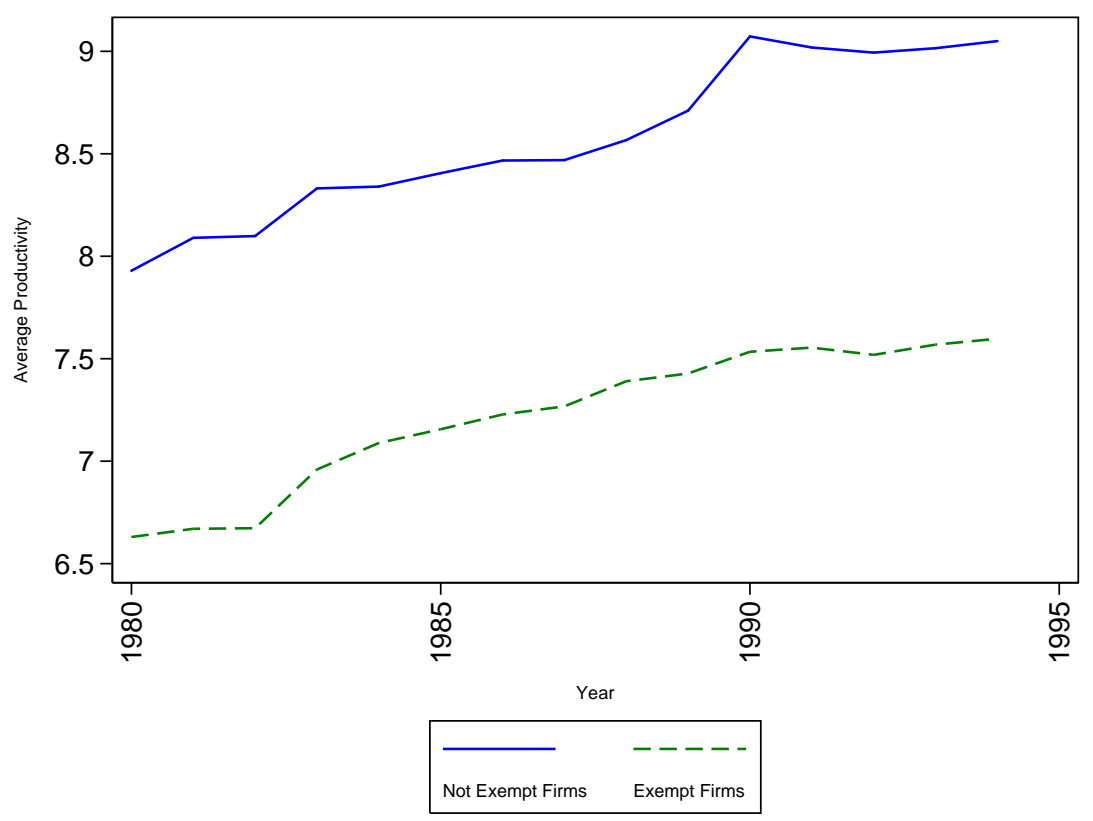

Figure 6: Trends in Productivity-Exempt and Not Exempt Firms

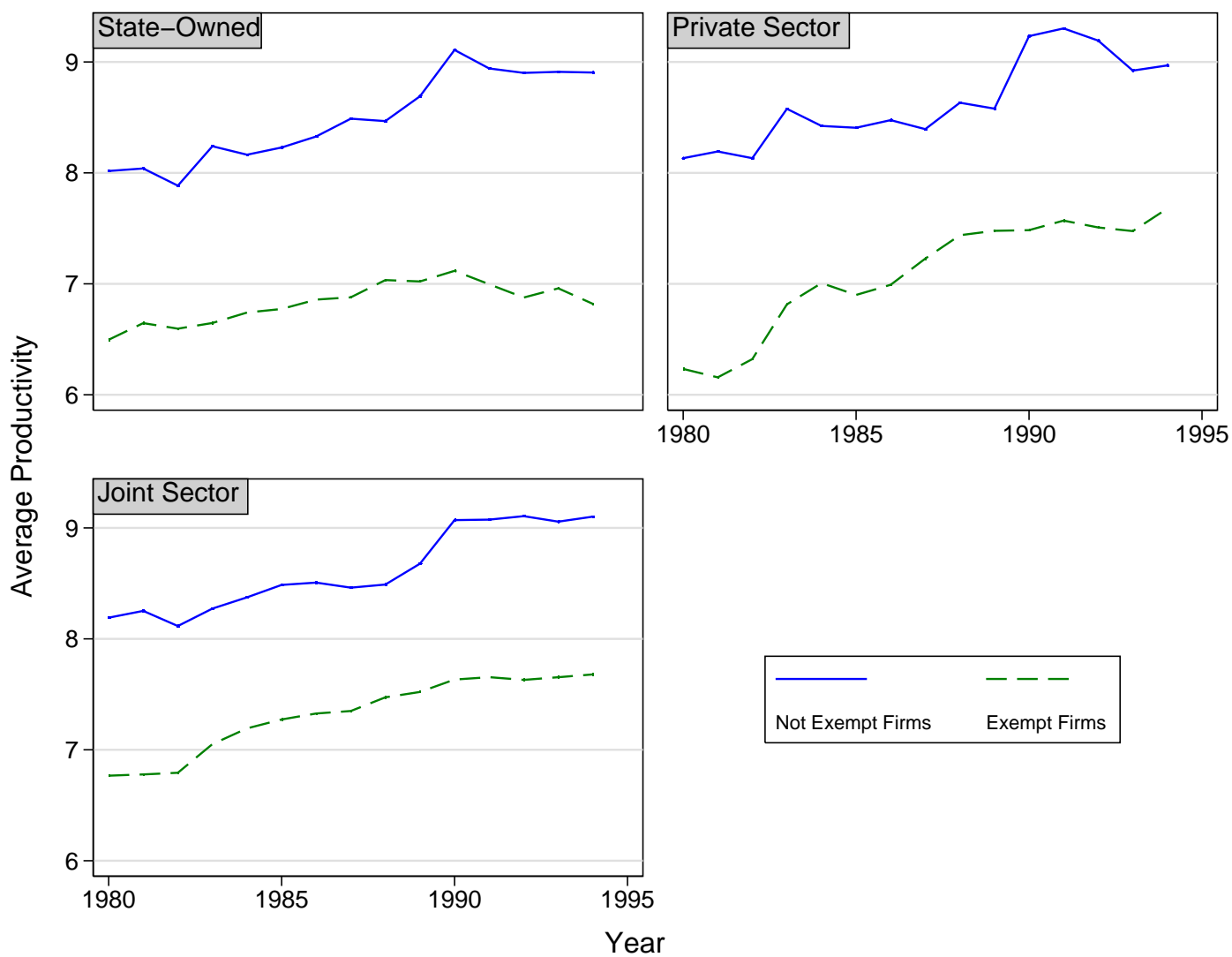

Figure 7: Trends in Productivity over Ownership Structure 

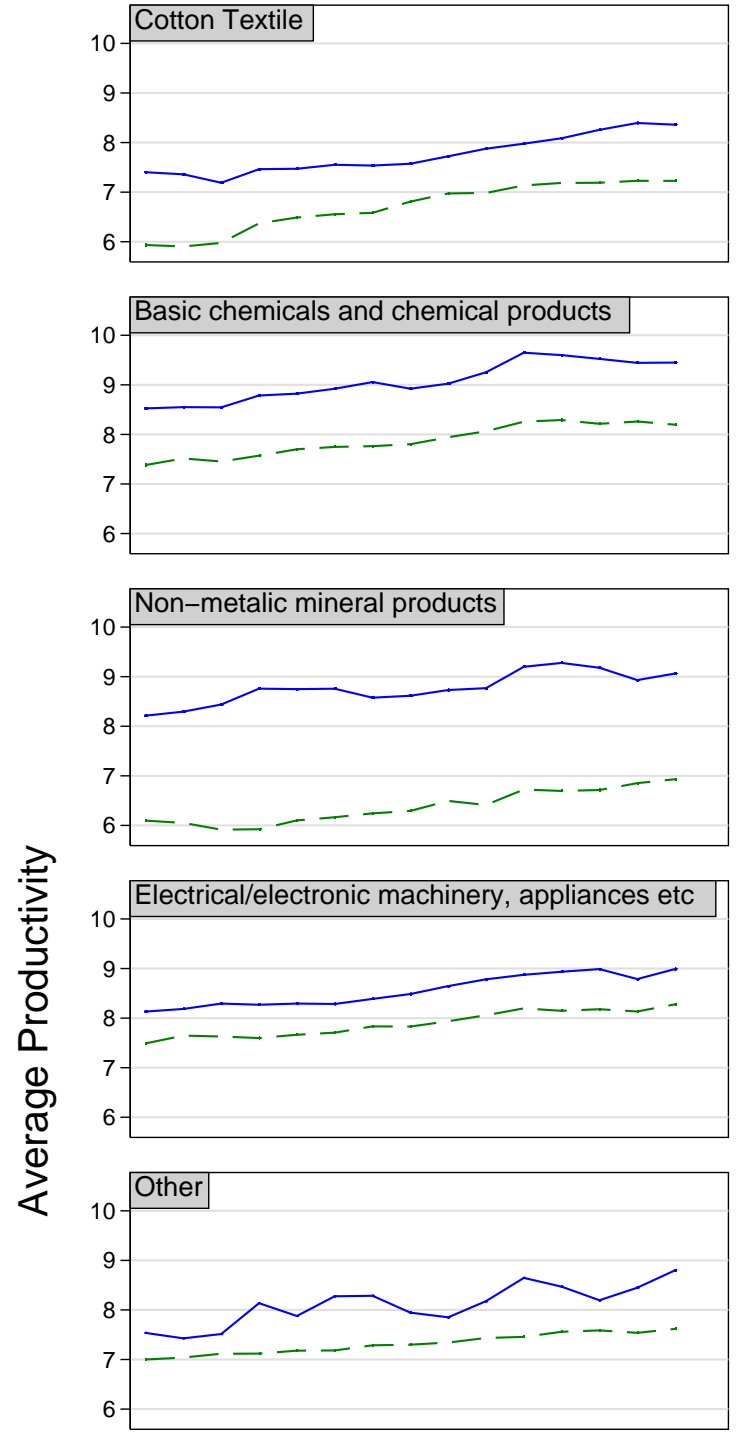

Textile Products

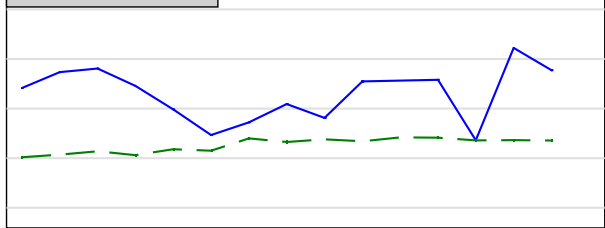

Rubber, plastic, petroleum \& coal products

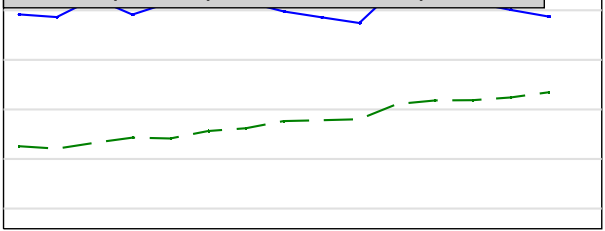

Machinery, machine tools and parts

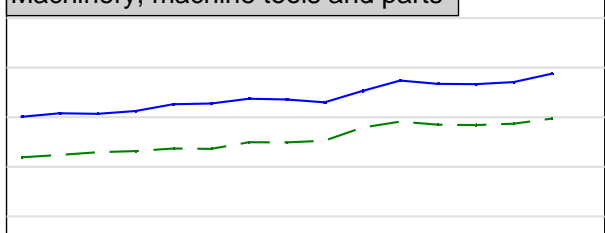

Transport equipment \& parts
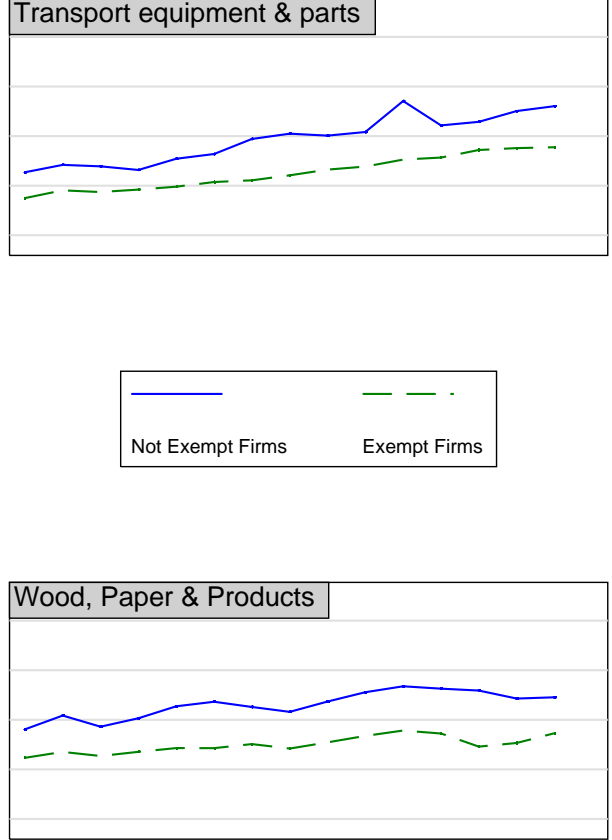

Food, beverage \& tobacco products

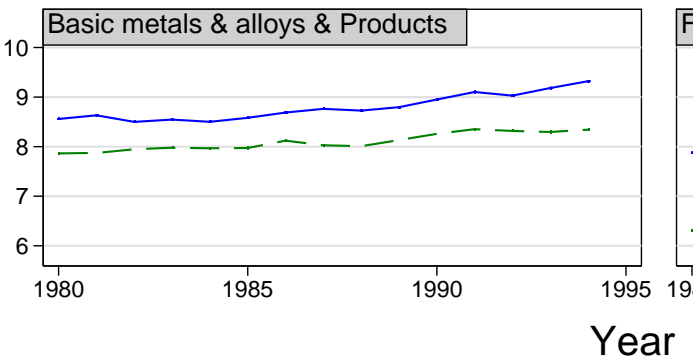

Figure 8: Trends in Productivity over Industries 


\section{References}

Acemoglu, D., Aghion, P., and Zilibotti, F. Distance to frontier, selection and economic growth. Journal of the European Economic Association, 4(1):37-74, March 2006.

Aghion, P. and Howitt, P. A model of growth through creative destruction. Econometrica, 60(2): 323-351, 1992.

Aghion, P., Dewatripont, M., and Rey, P. Competition, financial discipline and growth. Review of Economic Studies, 66:825-852, 1999.

Aghion, P., Harris, C., Howitt, P., and Vickers, J. Competition, imitation and growth with step-bystep innovation. Review of Economic Studies, 68(3):467-492, 2001.

Aghion, P., Burgess, R., Redding, S., and Zilibotti, F. The unequal effects of liberalization: Theory and evidence from india. mimeo. Harvard, London School of Economics and IIES, 2003.

Aghion, P., Burgess, R., Redding, S., and Zilibotti, F. The unequal effects of liberalization: Theory and evidence from india. Working Paper, London School of Economics, 2004.

Aghion, P., Burgess, R., Redding, S., and Zilibotti, F. Entry liberalization and inequality in industrial performance. Journal of the European Economic Association, 2(2-3):291-302, April 2005.

Angrist, J. and Evans, W. Schooling and labor market consequences of the 1970 state abortion reform. NBER Working Paper 5406, January 1996.

Das, D. Manufacturing productivity under varying trade regimes: India in the 1980s and 1990s. ICRIER Working Paper 107, 2003.

Das, G. India Unbound. From Independence to the Global Information Age. Profile Books Limited, $2^{\text {nd }}$ edition, 2000 .

Dasgupta, K. Report of the Monopolies Inquiry Commission. Government of India, 1965.

Delong, B. India since independence: An analytic growth narrative. In Rodrik, D., editor, Modern Economic Growth: Analytical Country Studies. 2001.

Djankov, S. and Murrell, P. Enterprise restructuring in transition: A quantitative survey. Journal of Economic Literature, XL:739-792, September 2002.

Dollar, D. and Kraay, A. Trade, growth, and poverty. Finance and Development, 38(3), September 2001.

Duflo, E. Schooling and labor market consequences of school construction in indonesia: Evidence from an unusual policy experiment. NBER Working Paper No. 7860, August 2000.

Dutt. Report of the Industrial Licensing Policy Enquiry Committee. Government of India, 1969.

Epifani, P. Trade liberalization, firm performance and labour market outcomes in the developing world: What can we learn from micro-level data. World Bank Working Paper No. 3036, 2003. 
Frankel, J. and Romer, D. Does trade cause growth? American Economic Review, 89(3):379-399, 1999.

Gertler, P. and Molyneaux, J. How economic development and family planning programs combined to reduce indonesian fertility. Demography, 31(1):33-63, 1994.

Hazari, R. Industrial Planning and Licensing Policy in India. Planning Commission, Government of India, 1967.

Hopenhayn, H. Entry, exit and firm dynamics in long-run equilibrium. Econometrica, 60(2): 1127-1150, 1992.

Krishna, P. and Mitra, D. Trade liberalization, market discipline and productivity growth: New evidence from india. Journal of Development Economics, 56:391-409, 1996.

Marathe, S. S. Regulation and Development: India's Policy Experience of Controls over Industry. SAGE Publications, second edition, 1989.

Melitz, M. The impact of trade on intra-industry reallocations and aggregate industry productivity. Econometrica, 71(6):1695-1725, November 2003.

Nickell, S. Competition and corporate performance. Journal of Political Economy, 104(4):724746, 1996.

P. Balakrishan, K. P. and Babu, M. Trade liberalization and productivity growth in manufacturing: Evidence from firm-level panel data. Economic and Political Weekly, pages 3679-3682, October 72000 .

Panagariya, A. India's economic reforms: What has been accomplished? what remains to be done? EDRC Policy Brief No.2, 2001.

Panagariya, A. India in the 19080's: Weak reforms, fragile growth. Mimeo. University of Maryland, 2002.

Panagariya, A. India in the 1980s and 1990s: A triumph of reforms. Mimeo. University of Maryland, 2004.

Ramakrishna, G. Study Group on Industrial Regulation and Procedures. Dept. of Industrial Development, Ministry of Industry, Government of India, February 1978.

Rodrik, D. and Rodriguez, F. Trade policy and economic growth: A skeptic's guide to the crossnational evidence. In Bernanke, B. and Rogoff, K., editors, Macroeconomics Annual 2000. MIT Press for NBER, 2001.

Rodrik, D. and Subramanian, A. From 'hindu growth' to productivity surge: The mystery of the indian growth transition. IMF Staff Papers, 2004.

Rosenzweig, M. and Wolpin, K. Evaluating the effects of optimally distributed programs: Child health and family planning interventions. American Economic Review, 37(3):265-289, December 1988 .

Sachs, J. and Warner, A. Economic reforms and the process of global integration. Brookings Papers on Economic Activity, pages 1-118, 1995. 
Schmidt, K. Managerial incentives and product market competition. The Review of Economic Studies, 64(2):191-214, 1997.

Sharma, G. Strategic complementarities between trade and industrial policies: A theoretical investigation. Mimeo. University of Maryland, May 2005.

Sivadasan, J. Barriers to Entry and Productivity: Micro-Evidence from Indian Manufacturing Sector Reforms. PhD thesis, University of Chicago, 2003.

Topalova, P. Trade liberalization and firm productivity: The case of india. IMF Working Paper $W P / 04 / 28,2003$.

Tybout, J. Linking trade and productivity:new research directions. The World Bank Economic Review, 6:189-211, 1992.

Tybout, J. Manufacturing firms in developing countries: How well do they do and why? Journal of Economic Literature, XXXVIII:11-44, March 2000.

Visaria, S. Legal reform and loan payment: The microeconomic impact of debt recovery tribunals in india. Mimeo. Columbia University, 2004. 


\section{A Background on Industrial Licensing in India}

\section{A.1 The Procedures}

After independence from the British in 1948, India adopted a mixed economy framework. The main pillars of this framework were a major role of the public sector in economic development and control of private industry. These principles were codified in the Industries (Development and Regulation) Act of 1951 (referred to as IDRA from now on). Under this act, the central government was given the right to issue licenses to firms for entering or for continuing production in manufacturing and certain basic industries were reserved for the public sector. That is, no private firm could produce in those industries.

The main aim of licensing was to direct investment of "precious" capital into the desired industries. Policy-makers at that time felt that private industry could not be trusted to invest in strategic and/or important industries like machine tools, steel, cement, chemicals etc and would probably invest in quick-return industries like consumer goods. Over time the licensing regime was used to fulfill a variety of policy purposes like encouragement to small-scale firms, control of large firms to prevent concentration of economic power in a few hands and to promote even growth in all regions of the country.

A license was a document that permitted a firm to continue/begin production in an industry. It was issued by the Ministry of Industry in New Delhi. Under the IDRA, 1951 all factories (defined as enterprizes that did not use power but employed more than 100 workers or enterprizes that used power and employed more than 50 workers) that were already operating or wished to operate in a specified list of industries were required by the government to obtain a license. The point of licensing was to direct investment into desirable directions and hence the Act specified a list of important industries in which licensing would exist. These industries are referred to as "First Schedule" industries.

All applications for license were debated upon by the Licensing Committee consisting of officers from the administrative ministry (Ministry of Industry), the Planning Commission and representatives of other government departments and the Director General of Technical Development (DGTD). This was the nodal body for technical recommendations. It gave recommendations to 
the licensing committee on crucial aspects of the project. These recommendations included the optimal size of the project, the technology to be used in the project, the amount of raw materialsdomestic and imported-required etc. The DGTD also granted annual allotments of raw materials once the license was granted. The licensing committee hearing was at the end a long chain of clearances that a firm had to obtain.

If the project was approved by the Committee then the firm was granted a "Letter of Intent" valid for one year. If the firm was able to show sufficient progress in the implementation of the project then it was issued a license. If production commenced within two years of the issue of the license then the license was permanent. Otherwise the license was revoked.

Conversations with officials who were on the licensing committee during the 1980 s revealed that the most important concern for the licensing committee while debating a particular case was the demand-supply situation of the good. The government maintained highly detailed records of the exact production of the good that was already taking place (all registered/licensed units were required to submit detailed monthly production reports) and so had information on the supply of the good. Information about capacity utilization of existing plants and demand projections from the Planning Commission were used to compute the demand side of the equation. The applicant was also required to give demand projections for the product. If it was felt that there was enough existing capacity to satisfy demand then the application was rejected irrespective of the quality of the proposed good and the nature and productivity of the technology that was proposed to be used. That is, the new project was not assessed on the merit of its efficiency, productivity or quality.

Another important facet was the type of the good. There was a disdain for variety in policymakers of the time. Competition was thought to be wasteful and Nehru once remarked "Why do we need nineteen brands of toothpaste?" as reported by Das $(2000)^{27}$. This was especially true for "luxury goods"-those which were deemed to be unnecessary and could not be afforded by the masses-like air conditioners, cosmetics etc. Another important consideration was import and foreign exchange requirements. A large number of applications were rejected because they required "too" much foreign exchange.

\footnotetext{
${ }^{27}$ Page 153.
} 


\section{A.2 Scope of Licensing}

The scope of a license was fairly broad especially from the late 1960s onwards. The conditions that a license specified were many. It specified the amount of output that a firm could produce. It was conditional on the proposed location of the project. Permission would be required to change location. The exact nature of the item to be produced was also specified and the firm needed to take permission or another license to change its product mix. Even the kind of technology and inputs that the firm could use in production (though not specified on the license) was determined by the Licensing Committee and the DGTD. This was because the most crucial raw materials (steel, cement, fuel etc) were controlled by the government and the firm needed to get annual allotments of these for production. Further a whole separate license was required for any machine, equipment, components or raw materials that needed to be imported. Even for that, the DGTD and the licensing committee made recommendations to the Capital Goods Licensing Committee about the nature and quantity of imports to be permitted.

According to Marathe $(1989)^{28}$, the initial purpose of licensing was not to take over decisionmaking from the firm. It was basically meant to guide investment. However, the precarious foreign exchange position in the 1960s meant that imports and hence, foreign exchange needed to be controlled stringently. In order to obtain a license to import raw materials or components, it became necessary for the firm to specify in much more detail the quantity and the exact nature of the good it would produce (in an example from Marathe (1989), the firm would need to specify that it planned to produce multi-spindle lathes instead of simply machine tools). This was because import licenses would be granted only for the exact components needed for lathes. Capacity constraints also started to be important in the licensing process because of the need to restrict imports. These details were primarily administrative in nature and had no business on a legal document like a license but over time, administrative convenience prevailed.

As the licensing mechanism became a tool for dealing with problems of administrative allocation of foreign exchange, the interpretation of various clauses of the IDRA became more and more strict and rigid. Even though the act itself took a lenient view of "substantial expansion" of production (under this clause the firm needs to take permission to substantially expand pro-

\footnotetext{
${ }^{28}$ Pages 85-86.
} 
duction), gradually capacity limits started being specified on licenses and over time, maximum capacity became equated with maximum production permissible. Marathe (1989) attributes both foreign exchange constraints as well as the control system feeding off of itself for the fact that by the 1970s,

“.....the judgement of the Government and Planners on questions such as the size, the nature of the equipment, the process and sometimes even the actual physical location of a unit often prevailed over the judgment of the entrepreneur concerned." 29.

\section{A.3 Implementation of the License Raj}

An important point that arises given the strict nature of the conditions that a firm was obligated to follow is whether the firm had any incentives to follow those conditions. Conversations with government of India officials who had been members of the licensing committee in the 1970s and 1980s as well as officers of the DGTD reveal that surprisingly, there were very little direct checks on the factory to see whether the conditions were being satisfied or not. That is, at first glance a license was a toothless piece of paper and there was no mechanism to make the entrepreneur follow its conditions. As a reminder, a license restricted entry into an industry, the amount produced by the firm, the product mix of the firm and sometimes, the location of the factory.

The main way in which licensing requirements were implemented were by an even more potent force than physical inspections. This force was the fact that all essential raw materials for production-steel, cement, coal, fuel, furnace oil, railway wagon movements, licenses to import equipment and raw materials etc-were not freely available in the market. Each and every firm was allotted a certain amount of these inputs each year based on the output limits specified on their license. Thus, it was very difficult for the entrepreneur to produce over the limit on his license since basic raw materials were allotted to him based on the licensed amount. Further licensing officials also reveal that during the actual licensing process there was almost no verification of the details provided by the entrepreneur. If he stated that his plant was located in district A then this was taken as given. However once the license was granted and the entrepreneur was petitioning the DGTD to allot him his quota of raw materials for the year, each and every aspect of the project was

\footnotetext{
${ }^{29}$ Marathe (1989), page 88
} 
thoroughly scrutinized to check whether conditions were satisfied. Further any direct assistance from the government (in the form of inputs, credit etc) legally obligated the firm to send detailed monthly production reports to the DGTD. These reports were also scrutinized for discrepancies.

Even though production without inputs allotted by the government would be difficult, it was not impossible since there was a black market for these inputs. This raises the possibility of entrepreneurs obtaining a license and then never going back to the DGTD for allotment of inputs. This way they could locate anywhere and produce whatever they wanted. Government officials were unwilling to put a number on the percentage of license-holders that were forced to come back to the DGTD for inputs and other permissions required for production. But when pressed, they revealed that $95 \%$ of license holders who wanted to commence production within two years of issue had to come to the DGTD for some allotment or the other and would have to pass a highly rigorous investigation of their project.

Officers gave an example of their power over the license-holder when questioned about the possibility that a lot of license-holders could have operated under the radar and flouted the license conditions. Suppose an entrepreneur was issued a license that specified that he was allowed to produce 10,000 units of a good per year. He would need cement to build the plant where production would take place and he would need equipment. The allotments of cement and equipment that were made by the government were based on 10,000 units. So the factory would be so small that it could not accommodate another machine even if the entrepreneur was able to obtain it from the black market.

A different perspective on this issue is available from several government of India reports. It was starting to become obvious in the 1960s itself that the licensing regime was not able to fulfill its primary objective-to direct investment in desired directions. Several committees and study groups were established during the 1960s and 1970s that studied the impact and performance of the licensing regime (Hazari (1967), Dutt (1969), Ramakrishna (1978) etc) also concluded that there was little follow-up of licenses to ensure that the projects were taking off. For example the Dutt Committee Report concluded that the licensing system had failed to prevent growth of capacity in less essential industries and could not be expected to ensure the creation of capacity in the more essential ones.

The Study Group on Industrial Regulation and Procedures under G.V. Ramakrishna (Ramakr- 
ishna (1978)) in its report stated that "Ěinstalled capacity was in several cases more than targeted capacity and in many more cases significantly lower than the targeted capacity" ${ }^{30}$. It also went on to observe that

"....the penal provisions of the Act have also not been very effective in enabling the enforcement of the conditions of industrial licenses. In many cases where actual production exceeds the licensed capacity by several times, it has not been possible effectively to use these provisions to bring such production in conformity with industrial licenses issued." 31.

It must be noted however, that these reports were comparing capacity created under the licensing regime to targets specified in the five year plans. That is, "excess capacity" as compared to what the planners expected was needed. This is no way meant that the existing firms had a free hand in determining their production levels or that there was free entry into any industry. That is, even if the firm was producing more than the amount specified on the license, it is by no means clear that it was producing its optimal quantity given the constraints on obtaining inputs.

The constraints that the licensing regime imposed on producers were severe. It was under the pain of imprisonment that a firm could produce above the amount specified on its license. A firm producing plastic buckets needed permission if it wanted to produce plastic toys instead. Availability of crucial raw materials was at the mercy of the DGTD and was done on the basis of the capacity specified on the license. There is also anecdotal evidence of shortages of many commodities. For example there was a ten year waiting list for scooters and yet the owner of the largest scooter company was hauled up about why he was producing more than his licensed capacity ${ }^{32}$. One of India's largest industrialists remarked in 1969 that

"I cannot decide how much to borrow, what shares to issue, at what price, what wages or bonus to pay and what dividend to give. I even need government permission for the salary I pay to a senior executive." 33 .

The reports that were commissioned in the 1960s and the 1970s reveal a crucial point- whether or not the licensing Raj was able to control capacity, it was most certainly able to control entry into an industry. In this respect licensing provided industrialists with a great deal of protection.

\footnotetext{
${ }^{30}$ Paragraph 1.20

${ }^{31}$ Paragraph 1.21

${ }^{32}$ Das (2000), page 175

${ }^{33}$ Das (2000), page 168
} 
Evidence of this started to emerge early in the licensing regime and the The Monopolies Inquiry Commission 1965 was one the earliest committees established to look into this. Though the purpose of the commission was to look at the practices of certain "large industrial houses", it gave broad recommendation regarding concentration and monopoly power in Indian industry. Based on interviews with a wide spectrum of Indian industry as well as analysis of detailed questionnaires that were sent to firms, it stated that

".....the requirement of law that new industries with capital over a specified amount $\check{E} \check{E}$ could not be started without a license is a formidable obstacle in the way of new entrepreneurs freely entering the lists." 34 .

Further,

"The system of controls on the shape of Industrial licensing however necessary from other points of views, has restricted the freedom of entry into industry and so helped to produce concentration",35.

The Committee also mentioned the issue of high costs of production in Indian manufacturing and averred that " The cost of production remains high due to the fact that top firms have not exerted themselves sufficiently......secure in the belief that in the absence of competition from abroad there was little risk of losing their market dominance". ${ }^{36}$.

The Hazari Committee 1967 (Hazari (1967)) also found evidence of industrialists pre-empting licenses. That is, a firm would send multiple applications for the same product. This ensured that it would be granted at least some of the planned capacity in that item, keeping out rivals. In no uncertain terms the committee remarked that

"The obligation on all units have fixed assets more than Rs. 25 lakhs to take out a license for new articles-applications which can be rejected out of hand on the ground of sufficient licensed (not necessarily actual) capacity keeps at bay existing large undertakings which might have the capacity to offer competitive products by feasible diversification. Enterprize plus imaginative understanding of licensing formalities thus enables the [name of large industrialist] to foreclose the market." 37

\footnotetext{
${ }^{34}$ Dasgupta (1965), page 7

${ }^{35}$ Dasgupta (1965), page 8

${ }^{36}$ Dasgupta (1965), page 142

${ }^{37}$ Hazari (1967), paragraph 13.5
} 
In conclusion, it seems that licensing was quite successful in providing firms protection from entry into the industry even if the stern conditions on capacity and output were not always implemented. Once a firm obtained a license, it held at best a monopolistic and at worse, an oligopolistic position in the industry. Even the threat of potential entry was low since there were reports of firms pre-empting capacity. That is, once a firm was granted a license in a particular item it would file multiple applications under different names so that all the "planned production capacity" in that item was under its control. This phenomenon has been mentioned by some of the government reports as well as anecdotal accounts. Government officials who scrutinized these applications report seeing as many as seven identical applications for the same item on the same day. Even the spelling mistakes in the applications were identical.

Thus, the licensing regime in India affected firm-level productivity and costs through its control on both the firm's ability and incentives to innovate, reduce costs, adopt new technology etc. The direct controls on outputs and inputs determined ability and the indirect control of entry determined incentives. Even if the direct controls where not implemented fully due to corruption etc, the effect of the indirect controls on incentives was very large as evident from the fact that each and every account of that time attributed the high costs, obsolete technology and low productivity of Indian industry to the lack of competition, among other factors.

\section{B Behavior of Non-licensed Firms}

In this appendix we analyze our unit-level data in greater detail. In particular we investigate the behavior of non-licensed firms across de-licensed and licensed industries. Our main conclusion from this analysis is that there is little evidence of the claim that firms may choose their size (defined by assets in plant, machinery, land and building) in anticipation of de-licensing.

\section{B.1 Nature of Asset Limits}

In order to show that firms were not choosing size endogenous with policy during the 1980s, we first demonstrate some statistics. The first and important point is whether the limit on assets in plant and machinery was binding for a non-licensed firm. If the definition is not truly binding then 
the magnitude of the problem of endogeneity is bound to be low. Table B.1 shows the utilization rates of non-licensed firms in various percentiles below the threshold.

We see that for the entire period, the top $1 \%$ of non-licensed firms were using on average only $80 \%$ of the rupee amount that was allowed to them. This rate drops off sharply as the top 5\% of firms use only $42.3 \%$ and the top $25 \%$ of firms use only $7.3 \%$ of the threshold.

That is, the threshold is binding only for the top $1 \%$ of firms which represent a very small number of firms compared to the total number of non-licensed firms. Further they represent a very small percentage of the total output of non-licensed firms (in 1985, the top $1 \%$ of firms accounted for $6.5 \%$ of output).

\begin{tabular}{lllll}
\hline Year & $\begin{array}{l}\text { Mean Assets in Plant, Machinery, } \\
\text { Land \& Buildings (Rs.) }\end{array}$ & \multicolumn{3}{c}{$\begin{array}{l}\text { Utilization Rates of Permissible Limit } \\
\text { within Percentiles of Threshold }\end{array}$} \\
\hline & & $99^{\text {th }}$ & $95^{\text {th }}$ & $90^{\text {th }}$ \\
\hline 1980 & $2.00 \mathrm{E}+06$ & 74.70 & 36.00 & 18.70 \\
1981 & $2.09 \mathrm{E}+06$ & 78.70 & 38.30 & 19.40 \\
1982 & $2.25 \mathrm{E}+06$ & 79.30 & 41.30 & 21.90 \\
1983 & $3.58 \mathrm{E}+06$ & 77.00 & 37.80 & 20.80 \\
1984 & $3.99 \mathrm{E}+06$ & 78.80 & 41.40 & 24.40 \\
1985 & $4.05 \mathrm{E}+06$ & 79.20 & 42.20 & 24.00 \\
1986 & $4.50 \mathrm{E}+06$ & 82.20 & 45.80 & 27.20 \\
1987 & $4.76 \mathrm{E}+06$ & 84.40 & 48.60 & 28.00 \\
1988 & $5.16 \mathrm{E}+06$ & 86.80 & 51.80 & 31.60 \\
1989 & $5.31 \mathrm{E}+06$ & 86.40 & 52.80 & 32.40 \\
1990 & $9.83 \mathrm{E}+06$ & 72.70 & 34.30 & 18.60 \\
1991 & $1.06 \mathrm{E}+07$ & 76.00 & 36.90 & 20.30 \\
1992 & $1.15 \mathrm{E}+07$ & 78.00 & 39.40 & 22.30 \\
1993 & $1.23 \mathrm{E}+07$ & 80.70 & 42.30 & 24.10 \\
1994 & $1.37 \mathrm{E}+07$ & 81.30 & 45.60 & 27.80 \\
\hline
\end{tabular}

Table B.1: Utilization Rates for Exempt firms

\section{B.2 Distribution of Firms Around the Threshold}

Another way in which we can check whether the asset limits were binding on non-licensed firms is by number of firms that were on or directly below the asset limit. If the limit was binding and firms were deliberately choosing to be under the threshold, we should see a large mass of firms on or just below the limit. In Tables B.2 and B.3 we present the frequency distribution of firms in 
bands around the threshold. In Table B.2, each column shows the number of firms that were $\mathrm{x} \%$ below the specified asset limit and in Table B.3, the number of firms that were $\mathrm{x} \%$ above the asset limit.

Column 2 of Table B. 2 shows that the number of firms that were $1 \%$ below the rupee threshold was few in number in absolute terms as well as relative to the total number of small firms. However one could argue that this might be because of indivisibility of investment in plant and machinery. Thus we present the number of firms that were within 5, 10, 20 and even 50\% of the rupee threshold. Even when we take firms that were spending more than $80 \%$ of the threshold amount (the column marked $20 \%$ ) we find that they accounted for only $2 \%$ of the total number of small firms during the 1980s. Thus there is not much evidence of bunching around the threshold for licensing.

Comparing Tables B.3 and B.2 we find that the frequency distribution of firms is very similar above and below the threshold. Suppose in general firms prefer to remain small and hence, under the licensing radar. But once a firm crosses the threshold it has incentive to invest a lot in plant and machinery. That is, once it is categorized as licensed by the government then it is in its interest to increase its assets in plant and machinery as much as it wants. This means that we should find that there aren't too many licensed firms that are really close to the threshold. But we see that there are as many firms in bands above the threshold as there are below. Further, licensed firms that are $1 \%$ above the cut-off constitute on average $0.9 \%$ of the total number of licensed firms (on average over the entire period). The corresponding figure for non-licensed firms that are $1 \%$ below the threshold is $0.04 \%$. If it were true that firms were choosing to remain small then the figures should be reversed. That is, the percentage of firms directly below the threshold should be much larger than the number of firms directly above the threshold.

Another point to note is that the rate of growth of the number of firms that are $1 \%$ below the threshold (Column 2 of Table B.2) is almost always higher than the rate of growth of the number of firms that are 20,50,80\% below the threshold (Column 6) as well as the rate of growth of all non-licensed firms ${ }^{38}$. This again points to the fact that firms were not deliberately suppressing

\footnotetext{
${ }^{38} \mathrm{We}$ also analyzed the rates of growth of assets in each band below the threshold and we find that the rate of growth declines as the amount of assets that a firm holds declines. That is, firms spending $80 \%$ of the threshold amount had higher rates of growth compared to firms spending 50 or $10 \%$ of the threshold amount. This means that larger non-licensed firms were growing faster. This would not have been true if firms were deliberately trying to keep assets
} 
their investment in plant and machinery in order to remain below the threshold.

We also conducted similar experiments for the capital-labor ratio implied by the threshold for licensing in order to test whether exempt firms choose their capital-labor ratio in response to the anticipation of deregulation? Analysis of data reveals that this is not the case. When we compare the behavior of Exempt firms across deregulated and regulated industries, pre and post reforms ${ }^{39}$ we find that the distribution of capital-labor ratio is very similar across the two sets of industries (de-licensed and licensed) in both periods (pre and post reforms). That is, there is no systematic tendency towards using the capital to labor ratio as a means towards preparing for anticipated deregulation.

\begin{tabular}{lllllllll}
\hline Year & \multicolumn{7}{c}{ Cumulative Distribution of Firms in Bands Below the Cut-off } \\
& $1 \%$ & $5 \%$ & $10 \%$ & $20 \%$ & $50 \%$ & $80 \%$ & $90 \%$ & Total \\
\hline 1980 & 3 & 36 & 63 & 249 & 636 & 2298 & 3549 & 18,530 \\
1981 & 5 & 38 & 74 & 292 & 727 & 2375 & 3680 & 18,947 \\
1982 & 8 & 34 & 74 & 304 & 848 & 2714 & 4145 & 19,815 \\
1983 & 5 & 33 & 61 & 281 & 694 & 2518 & 3833 & 17,960 \\
1984 & 8 & 35 & 76 & 339 & 774 & 2692 & 4072 & 17,213 \\
1985 & 3 & 35 & 73 & 346 & 793 & 2787 & 4256 & 17,895 \\
1986 & 7 & 37 & 91 & 378 & 918 & 3015 & 4616 & 17,371 \\
1987 & 9 & 46 & 114 & 413 & 1021 & 3367 & 5147 & 18,439 \\
1988 & 10 & 66 & 138 & 457 & 1190 & 3501 & 5470 & 18,425 \\
1989 & 9 & 84 & 147 & 509 & 1240 & 3887 & 5876 & 18,875 \\
1990 & 5 & 20 & 56 & 252 & 622 & 2565 & 4060 & 19,389 \\
1991 & 7 & 34 & 68 & 271 & 717 & 2739 & 4370 & 19,512 \\
1992 & 8 & 44 & 86 & 337 & 884 & 3149 & 5025 & 21,024 \\
1993 & 12 & 57 & 99 & 389 & 995 & 3445 & 5467 & 21,787 \\
1994 & 9 & 54 & 109 & 429 & 1132 & 4023 & 6149 & 22,252 \\
\hline
\end{tabular}

Table B.2: Distribution of Firms Below the Threshold for Licensing

low.

${ }^{39}$ Figures and tables available from author upon request. 


\begin{tabular}{lllllllll}
\hline Year & \multicolumn{1}{c}{ Cumulative Distribution of Firms in Bands Above the Cut-off } \\
& $1 \%$ & $5 \%$ & $10 \%$ & $20 \%$ & $50 \%$ & $80 \%$ & $90 \%$ & Total \\
\hline 1980 & 3 & 27 & 49 & 183 & 309 & 503 & 517 & 575 \\
1981 & 3 & 20 & 46 & 218 & 350 & 569 & 590 & 619 \\
1982 & 8 & 42 & 69 & 251 & 441 & 713 & 741 & 782 \\
1983 & 3 & 31 & 76 & 225 & 366 & 522 & 542 & 581 \\
1984 & 4 & 35 & 70 & 244 & 409 & 602 & 622 & 686 \\
1985 & 10 & 39 & 88 & 264 & 452 & 685 & 711 & 785 \\
1986 & 8 & 38 & 82 & 289 & 495 & 787 & 814 & 887 \\
1987 & 12 & 52 & 88 & 346 & 598 & 931 & 962 & 1,031 \\
1988 & 11 & 52 & 93 & 350 & 589 & 965 & 1005 & 1,192 \\
1989 & 13 & 50 & 98 & 348 & 632 & 1021 & 1066 & 1,346 \\
1990 & 7 & 33 & 54 & 185 & 316 & 462 & 473 & 565 \\
1991 & 6 & 39 & 82 & 243 & 374 & 550 & 565 & 674 \\
1992 & 8 & 45 & 93 & 258 & 452 & 679 & 699 & 867 \\
1993 & 8 & 54 & 102 & 279 & 490 & 764 & 794 & 1,026 \\
1994 & 10 & 65 & 123 & 351 & 585 & 914 & 958 & 1,232 \\
\hline
\end{tabular}

Table B.3: Distribution of Firms Above the Threshold for Licensing

\section{Specification Test using Special Industries}

In Table C.1 we report the results of our falsification regression using the group of special industries in which no firm had exemption from licensing. An assumption of our identification strategy is that the coefficient on the interaction of exemption status and de-licensing should be insignificant for this group of industries. In Column 1, the coefficients are from estimation of Equation 2 on the group of industries were exemption from licensing was not available (the Schedule IV and V industries). As we see the co-efficient on the interaction of de-licensing with exemptions status is not significant. That is, there is no exemption-based response to de-licensing in these industries. This shows that our identification assumption holds.

However we might be worried that this is not a powerful test since the number of observations is small as compared to the full sample. Note that the magnitude on the interaction coefficient is large in magnitude.

Another area of concern could be the schedule IV and Schedule V industries may not have enough variation in productivity as compared to other industries (where exemption from licensing was allowed) and this might affect the power of our specification test. However the coefficient of variation in log output per worker is $17 \%$ for Schedule IV and V industries as compared with $20 \%$ 
for other industries.

In Column 2 of Table C.1 we present another specification test. We estimate modified Equation 2 for all industries (including schedule IV and V industries). We define Special $_{j t}=1$ if industry $j$ was included in Schedule IV or V in year $t, 0$ otherwise and estimate

$$
\begin{aligned}
y_{i j t s}=\beta_{0} & +\alpha_{j}+\delta_{t}+\beta_{1} \text { De }_{j t}+\beta_{2} \text { NotExempt }_{i t}+\beta_{3} \text { De }_{j t} \text { Not Exempt }_{i t} \\
& +\beta_{4} \text { Special }_{j t}+\beta_{5} \text { De }_{j t} \text { NotExempt }_{i t} \text { Special }_{j t}+\eta X_{i j t s}+\varepsilon_{i j t s}
\end{aligned}
$$

That is, we include the special industries (without exemption from licensing) into our main regression and allow them to have a different intercept and slope as compared to the other industries. By pooling all industries we increase the power of our test. The first thing to notice is that coefficient on the interaction of exemption status and de-licensing is very small in magnitude and insignificant for the special industries. Further we find that we accept the hypothesis that $\beta_{3}+\beta_{5}=0$ i.e. we accept the hypothesis that there is no variation in the performance of firms in de-licensed industries around the threshold for licensing, for the set of industries where this threshold was not relevant.

\begin{tabular}{lll}
\hline & Only Special Industries & All industries \\
\hline NotExempt & $0.637^{* * *}$ & $0.613^{* * *}$ \\
& {$[0.094]$} & {$[0.083]$} \\
De & -0.001 & $-0.042^{*}$ \\
& {$[0.070]$} & {$[0.025]$} \\
De*NotExempt & 0.107 & $0.146^{* *}$ \\
& {$[0.107]$} & {$[0.065]$} \\
Special & & 0.072 \\
& & {$[0.068]$} \\
Special*De*NotExempt & & -0.011 \\
& & {$[0.079]$} \\
Constant & $6.252^{* * *}$ & $6.285^{* * *}$ \\
& {$[0.150]$} & {$[0.151]$} \\
Observations & 172297 & 206640 \\
R-squared & 0.51 & 0.51 \\
\hline Industry FE & Yes & Yes \\
(4-digit) & & \\
State FE & Yes & Yes \\
Year FE & Yes & Yes \\
\hline F-test on restriction & & \\
$\beta_{3}+\beta_{5}=0$ & & 1.85 \\
\hline
\end{tabular}

Table C.1: Falsification Test using Special Industries. Special refers to Schedule IV and V industries that did not have size-based exemption from licensing. 


\section{Specification Test using Various Thresholds for Exemption}

In this appendix we check our specification using various thresholds for exemption. Our identification assumption implies that there should be variation in the response of firms to de-licensing around the actual threshold for licensing. For all other hypothetical thresholds, the interaction coefficient between de-licensing and exemption status should be insignificant.

In order to conduct this specification test we use the following methodology. The actual exemption threshold is in nominal rupees and this nominal value was changed twice over our time period. Given the span of the data and possibility of inflation, we can not use absolute deviations from the actual threshold to generate our hypothetical thresholds.

We generate our hypothetical thresholds in the following way. For each year and conditional on actual exemption status, we sort firms according to their assets in plant, machinery, land and building. Then we take the rupee amount below which there are $10 \%$ of the firms in that year and assume those firms are Exempt from licensing requirements. That is, we take the $10^{\text {th }}$ percentile as our first threshold. This means that 10\% of actually Exempt firms are treated as Exempt and 90\% of actually exempt firms are treated as Not Exempt. Similarly, the next threshold is defined as the rupee amount of the $20^{\text {th }}$ percentile and hence $20 \%$ of actually Exempt firms are treated as Exempt and the other $80 \%$ are shifted into the Not Exempt category. Thus at the $90^{\text {th }}$ percentile, we treat 90\% of actually Exempt firms as exempt and 10\% of actually exempt firms as Not Exempt.

Similarly we sort the firms above the actual threshold in each year according to their assets and take the various percentiles as our cut-off points. Thus the first cut-off above the actual threshold shifts $10 \%$ of the actually Not Exempt firms as Exempt, the second cut-off shifts $20 \%$ of actually Not Exempt firms into the Exempt category etc.

Thus we continually shift firms from the Not Exempt category into the Exempt category as we approach the actual threshold and then go beyond it.

We define $N E(x)_{i t}=0$ if firm $\mathrm{i}$ is in the $\mathrm{x}^{\text {th }}$ percentile in year $\mathrm{t}, 1$ else and estimate the equation below for different values of $\mathrm{x}$

$$
y_{i j t s}=\beta_{0}+\alpha_{j}+\delta_{t}+\beta_{1} D e_{j t}+\beta_{2} N E(x)_{i t}+\beta_{3} D e_{j t} N E(x)_{i t}+\eta X_{i j t s}+\varepsilon_{i j t s}
$$

Note that in this specification test we only include the years 1980-91. This is because size- 
based exemption from licensing was completely removed during the 1991 reforms. That is, all firms in licensed industries were licensed and all firms in de-licensed industries were de-licensed. This means that this robustness test is valid only for the period in which exemption from licensing is an issue for firms.

In Table D.1 we present the coefficients, standard errors, t-statistics and z-statistics for the interaction term $D e_{j t} N E(x)_{i t}$. If our identification strategy is correct then the interaction terms should be insignificant far from the actual threshold and should become more significant as we approach the threshold from either side. As can be seen the interaction coefficient is not significant at either extremes and rises in significance as we approach the threshold. Further as can be seen in Figure D.1 (given below) where we plot the coefficient estimates and their confidence interval on distance from the actual threshold, the confidence interval of the coefficients is very large at the extremes and narrows as we approach the actual threshold. That is, the coefficients are much more precise near the actual threshold than away from it.

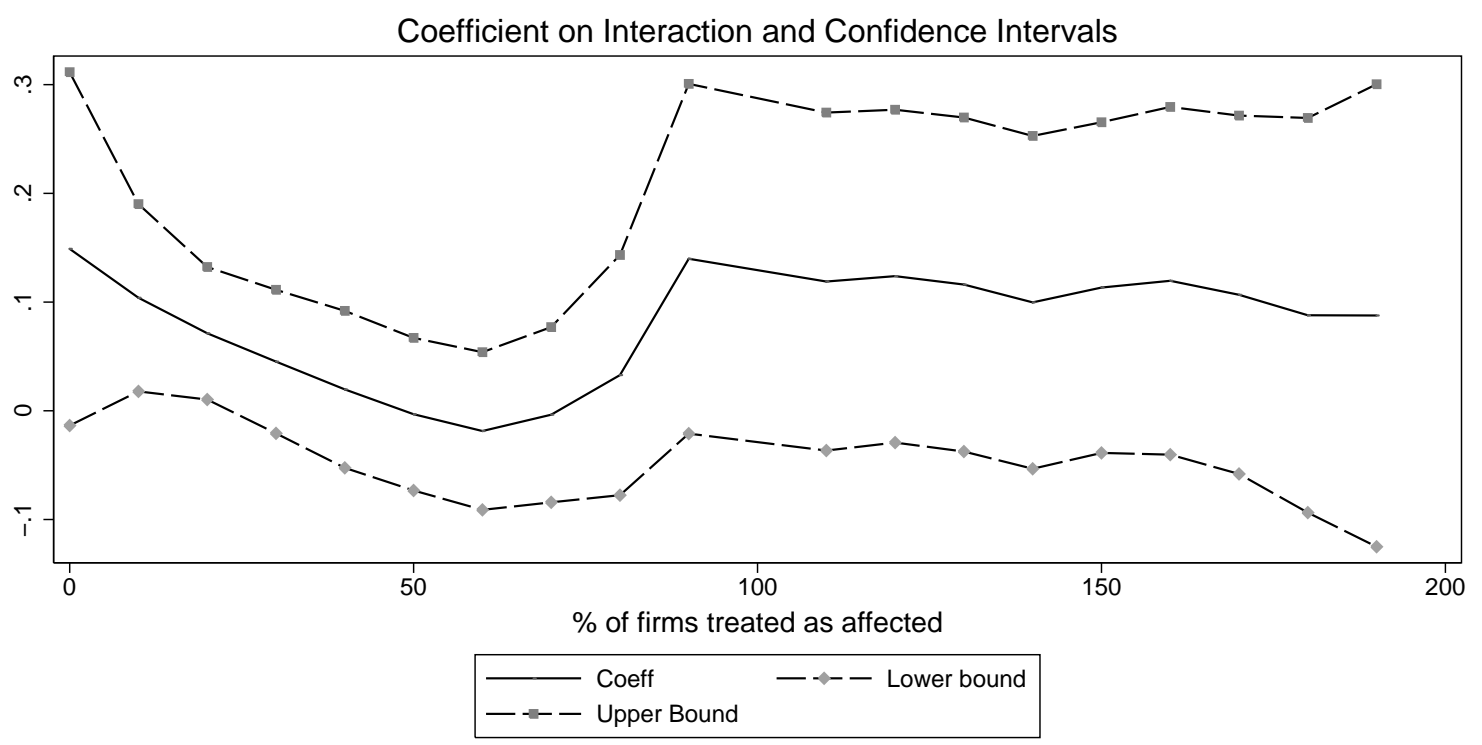

Figure D.1: Coefficient on Interaction and Confidence Intervals 


\begin{tabular}{lllll}
\hline $\begin{array}{l}\text { \% of actually Exempt firms } \\
\text { treated as Not Exempt }\end{array}$ & $\begin{array}{l}\text { Coefficient on } \\
\text { Interaction }\end{array}$ & $\begin{array}{l}\text { Standard } \\
\text { Error }\end{array}$ & Z-statistic & t-statistic \\
\hline 90 & 0.13987 & 0.08183 & 1.709286 & 1.71 \\
80 & 0.0328603 & 0.056206 & 0.584645 & 0.58 \\
70 & -0.0035671 & 0.040994 & -0.08702 & -0.09 \\
60 & -0.01859 & 0.036891 & -0.50392 & -0.5 \\
50 & -0.0031225 & 0.035701 & -0.08746 & -0.09 \\
40 & 0.0197247 & 0.036726 & 0.537079 & 0.54 \\
30 & 0.0452736 & 0.033586 & 1.347974 & 1.35 \\
20 & 0.0713353 & 0.031008 & 2.300567 & 2.3 \\
10 & 0.1040062 & 0.043816 & 2.373698 & 2.37 \\
Actual threshold & 0.1489872 & 0.08268 & 1.801976 & 1.8 \\
110 & 0.1189155 & 0.079071 & 1.503915 & 1.5 \\
120 & 0.1238649 & 0.077874 & 1.590587 & 1.59 \\
130 & 0.1161601 & 0.078147 & 1.486438 & 1.49 \\
140 & 0.0997598 & 0.077873 & 1.281056 & 1.28 \\
150 & 0.113357 & 0.077358 & 1.465358 & 1.47 \\
160 & 0.1195946 & 0.081337 & 1.470359 & 1.47 \\
170 & 0.1067452 & 0.083844 & 1.273135 & 1.27 \\
180 & 0.0878918 & 0.092328 & 0.951953 & 0.95 \\
190 & 0.0876862 & 0.108197 & 0.81043 & 0.81 \\
\hline
\end{tabular}

Table D.1: Coefficient on Interaction for Various Thresholds 